Solid-Supported Synthesis of Polymerizable Lanthanideion Chelating Lipids for Protein Detection

Nadi, S.; Santos, M.; Haldar, M. K.; Roy, B. C.; Mallik, S.; Campiglia, A. D.

\title{
NMR spectra of the reported compounds
}




\section{Lipid 1, ${ }^{1} \mathrm{H}$ NMR Spectrum:}

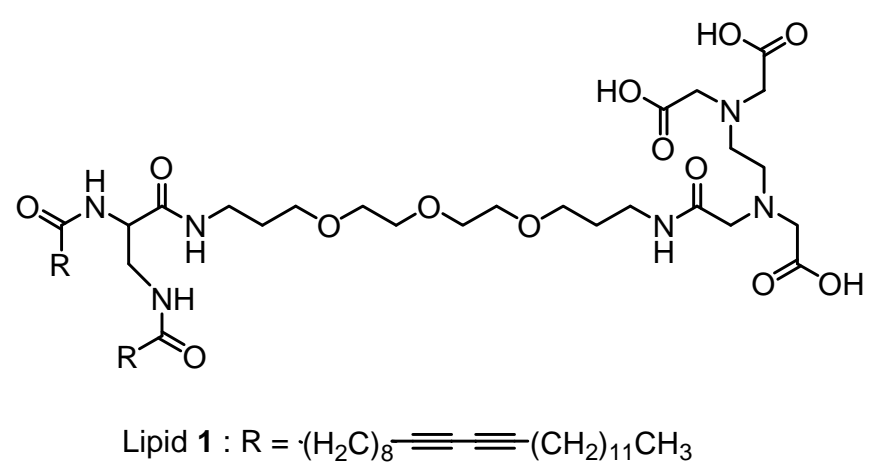

SN202_1

Pulse Sequence: s2pul

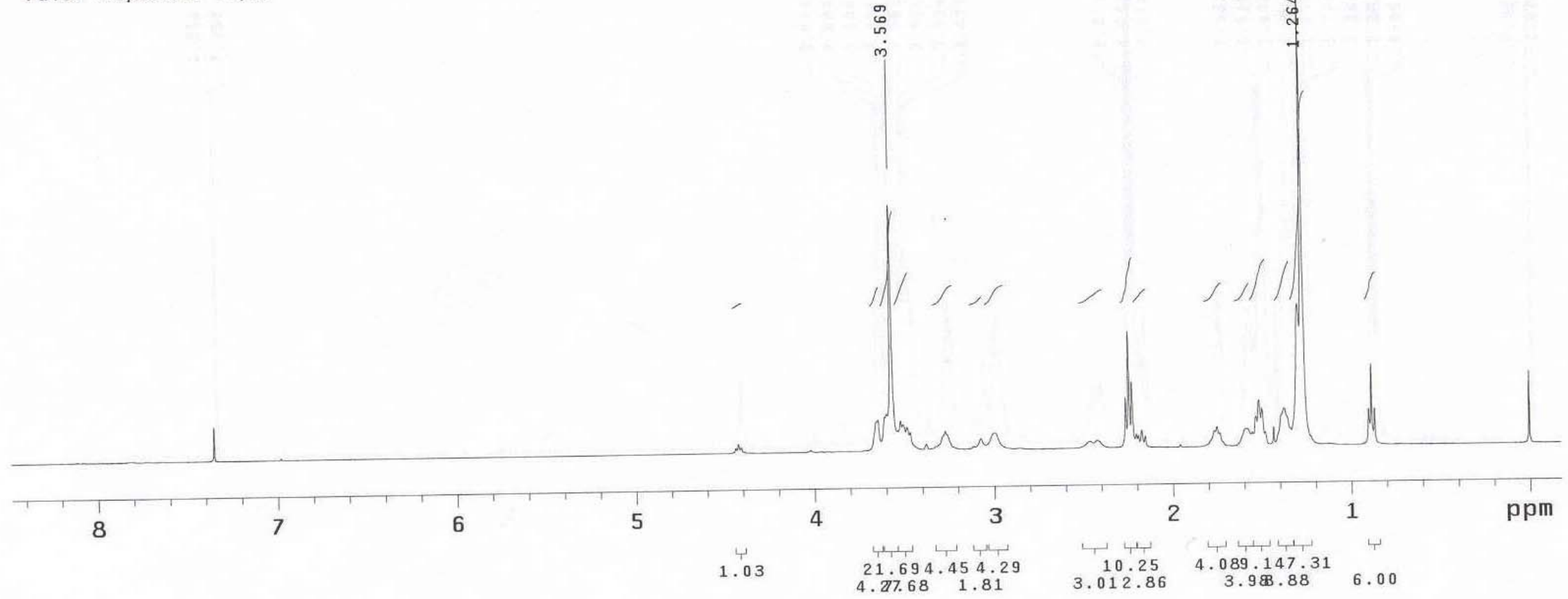




\section{Lipid 1, ${ }^{13} \mathrm{C}$ NMR Spectrum:}

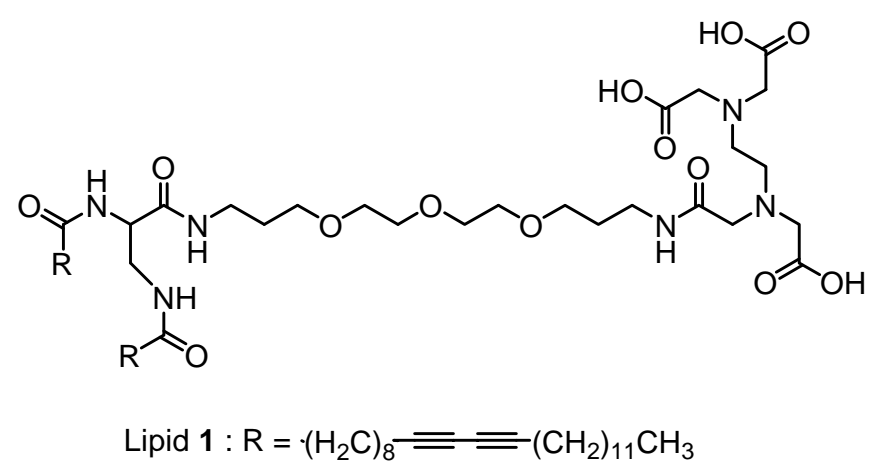

SN202

Pulse Sequence: s2pul

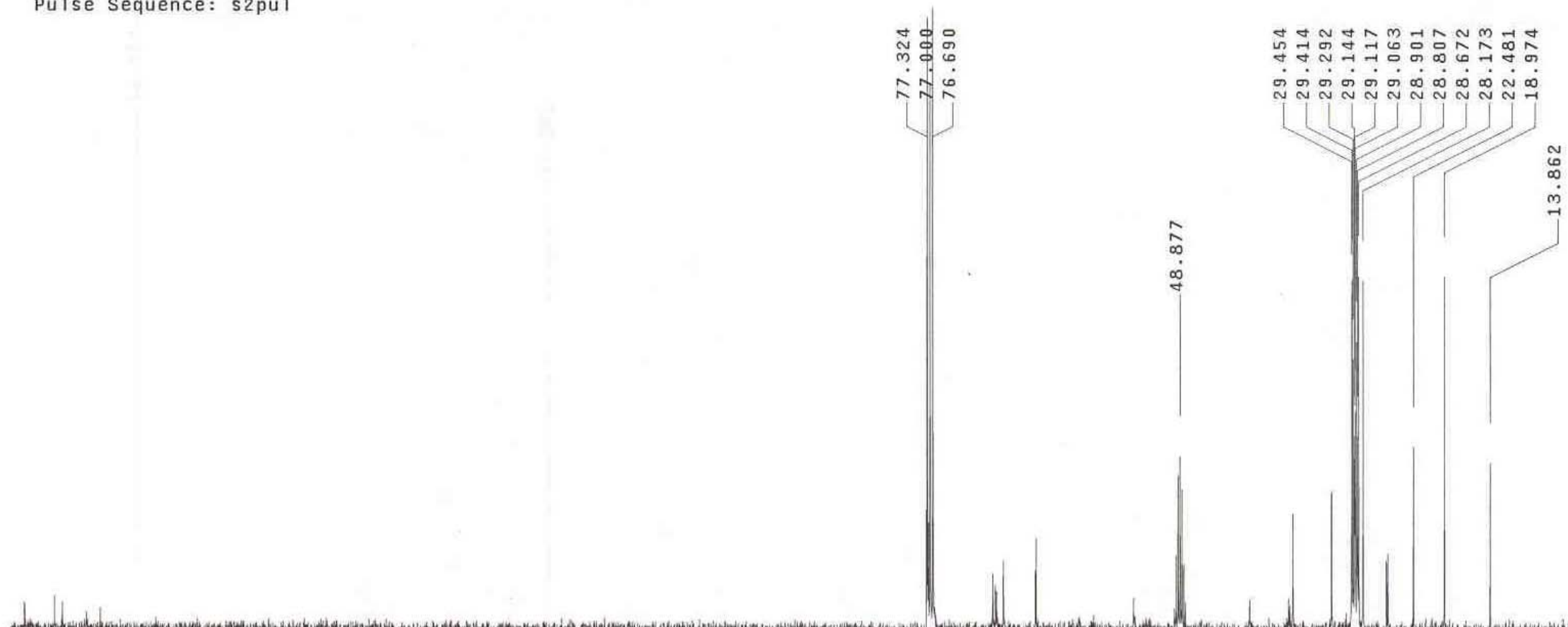

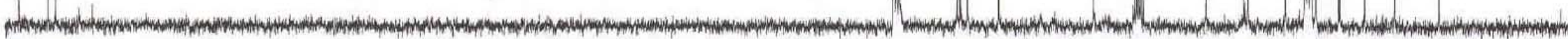

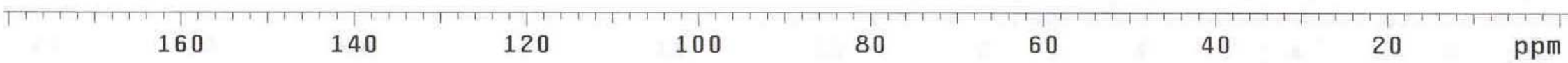




\section{Lipid 2, ${ }^{1} \mathrm{H}$ NMR Spectrum:}

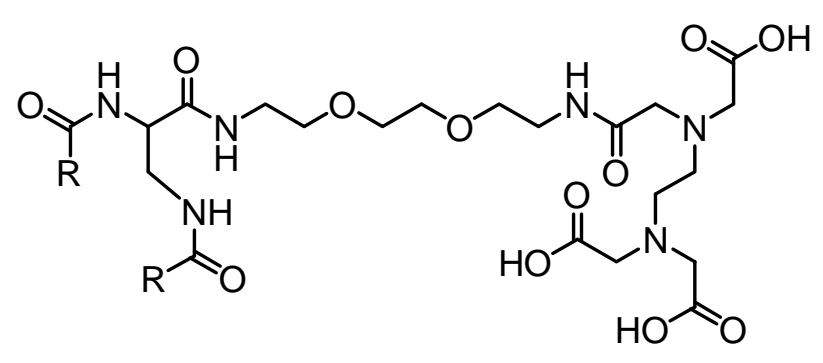

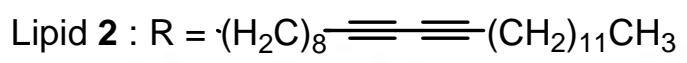

SN208

Pulse sequence: s2pul

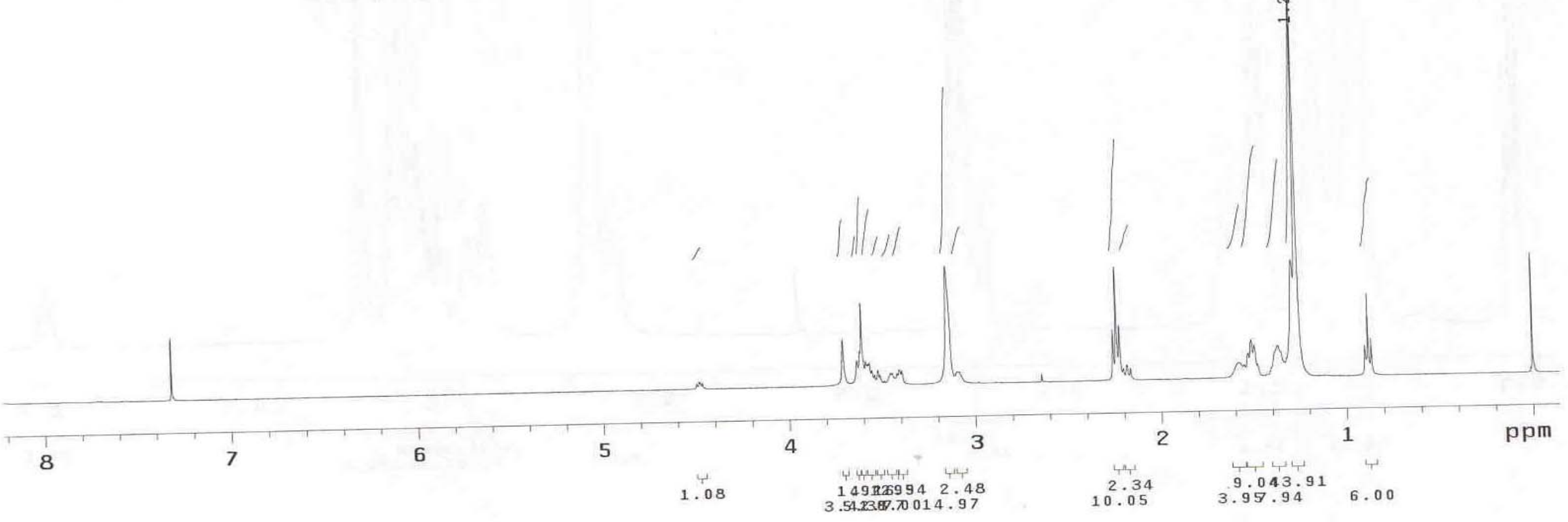




\section{Lipid 2, ${ }^{13}$ C NMR Spectrum:}

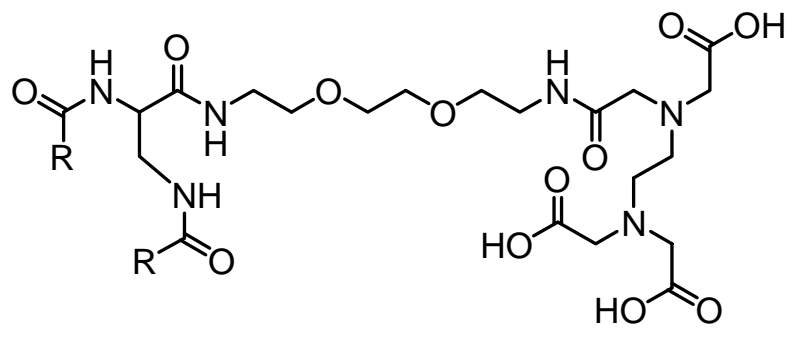

Lipid $2: \mathrm{R}=\cdot\left(\mathrm{H}_{2} \mathrm{C}\right)_{8}=\left(\mathrm{CH}_{2}\right)_{11} \mathrm{CH}_{3}$

SN208 diOXapOIYMEDTAOH3

Pulse sequence: s2pul

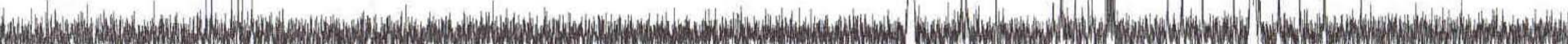
He
180
160
140
120
100
80
60
40
20
0 ppm 


\section{Lipid 3, ${ }^{1} \mathrm{H}$ NMR Spectrum:}

SN90 sat_orn

$500 \mathrm{MHZ}$

zarucateo kax lys.

Sample directory: proton=test_02Mar2000
File: PROTON

Pulse Sequence: s2pul

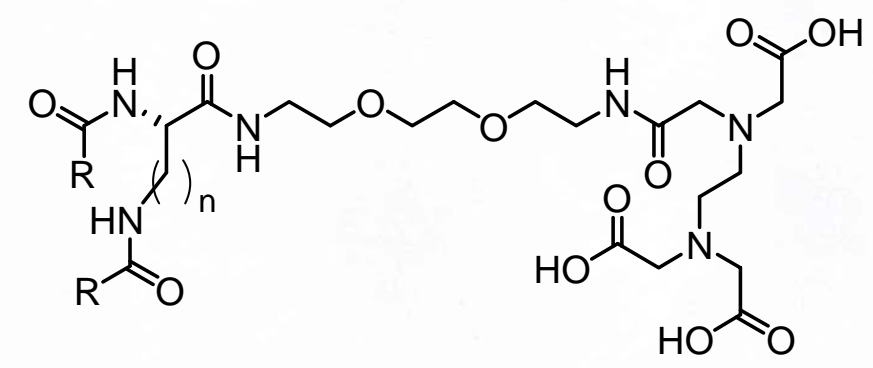

$\mathrm{n}=3$ : Lipid 3: $\mathrm{R}=-\left(\mathrm{CH}_{2}\right)_{16} \cdot \mathrm{CH}_{3}$

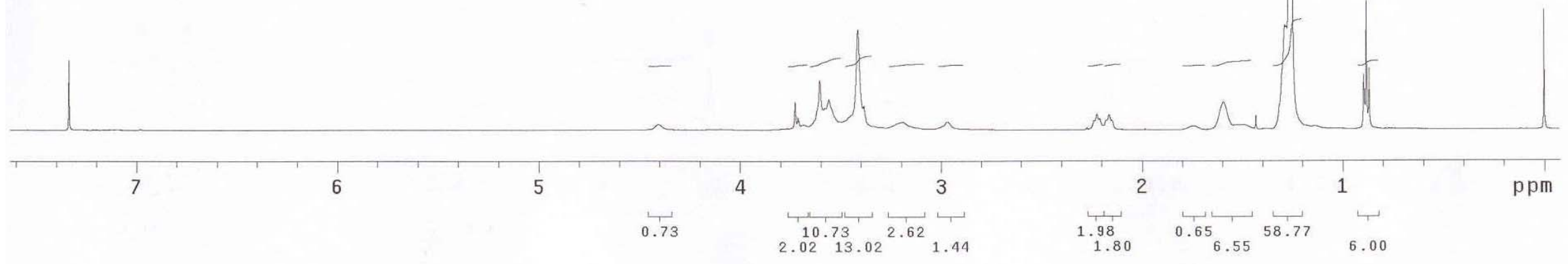




\section{Lipid 3, ${ }^{13}$ C NMR Spectrum:}

SN90 orn_sat $\quad 500 \mathrm{MHz}$

Sample directory: eb-chloroform_01Mar2000

Pulse Sequence: s2pur

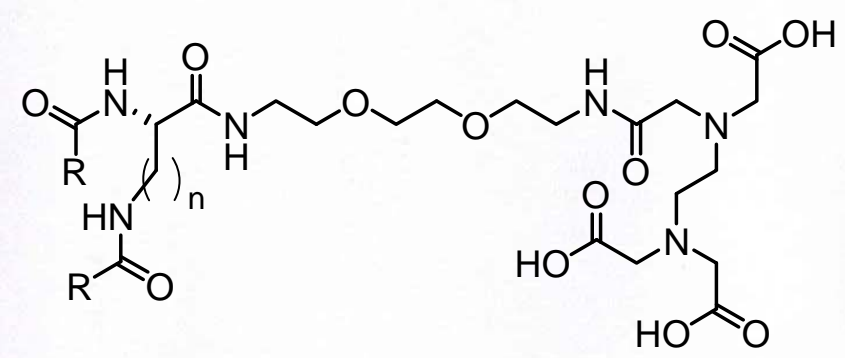

$\mathrm{n}=3:$ Lipid 3: $\mathrm{R}=-\left(\mathrm{CH}_{2}\right)_{16}-\mathrm{CH}_{3}$ 


\section{Lipid 4, ${ }^{1} \mathrm{H}$ NMR Spectrum:}

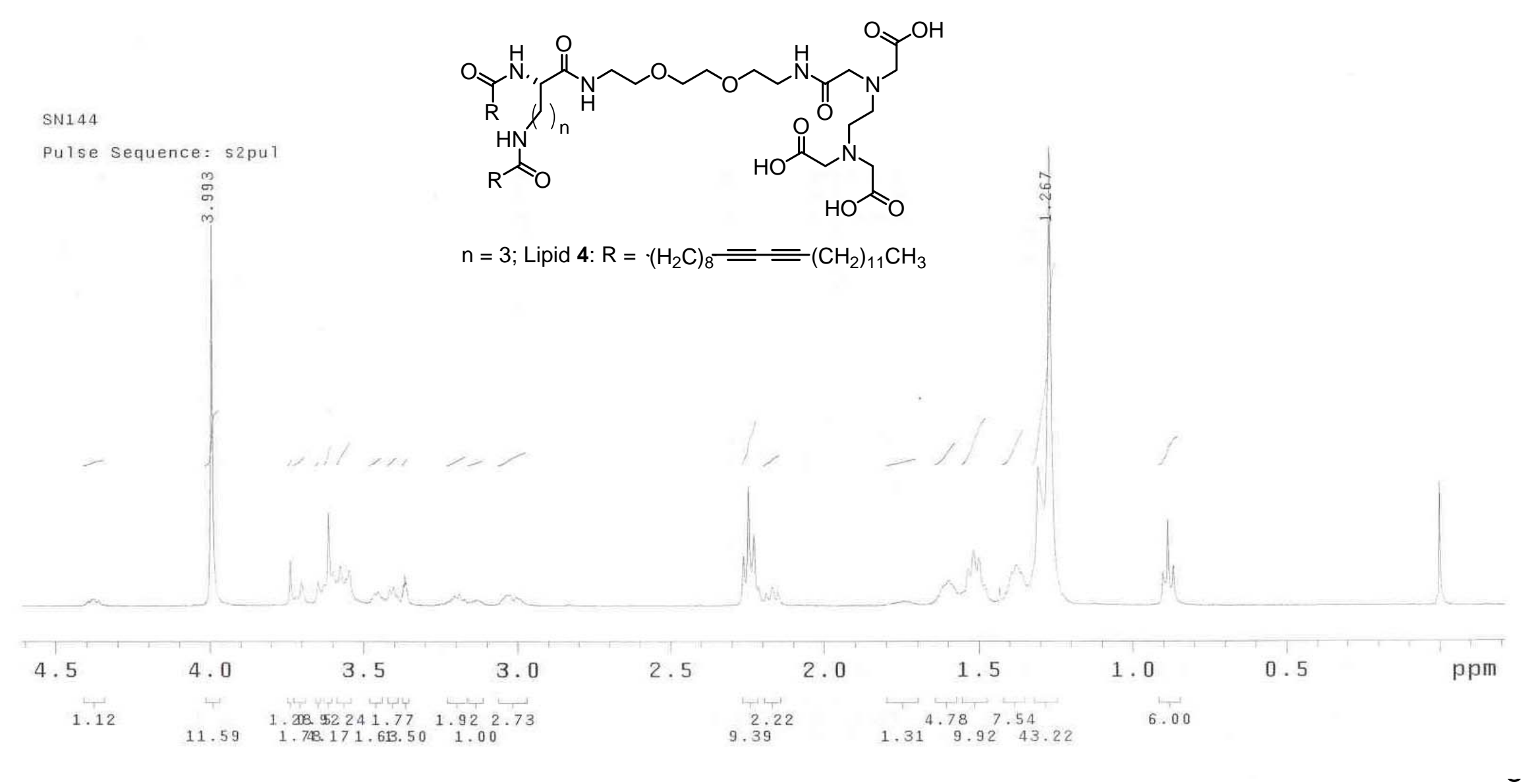




\section{Lipid 4, ${ }^{13}$ C NMR Spectrum:}

SN144 Orn_polym_dioxa

Pulse Sequence: s2pul

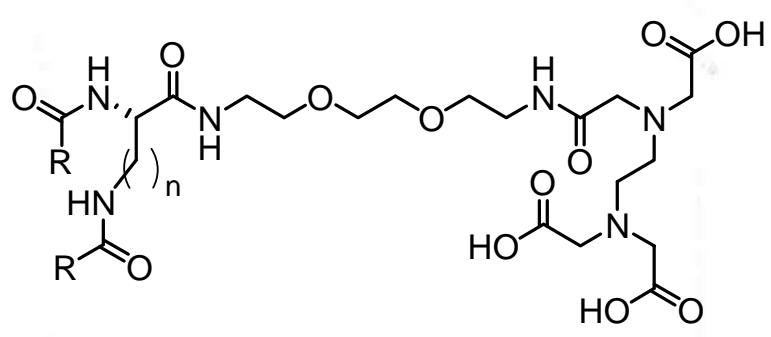

$\mathrm{n}=3$; Lipid 4: $\mathrm{R}=\cdot\left(\mathrm{H}_{2} \mathrm{C}\right)_{8} \equiv\left(\mathrm{CH}_{2}\right)_{11} \mathrm{CH}_{3}$

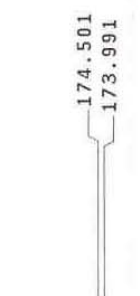

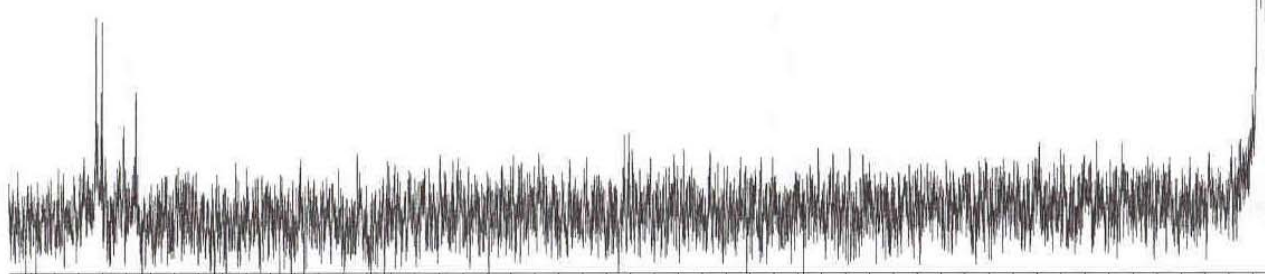

160

140

120

100

80

60

40

20

ppm 


\section{Lipid 5, ${ }^{1} \mathrm{H}$ NMR Spectrum:}

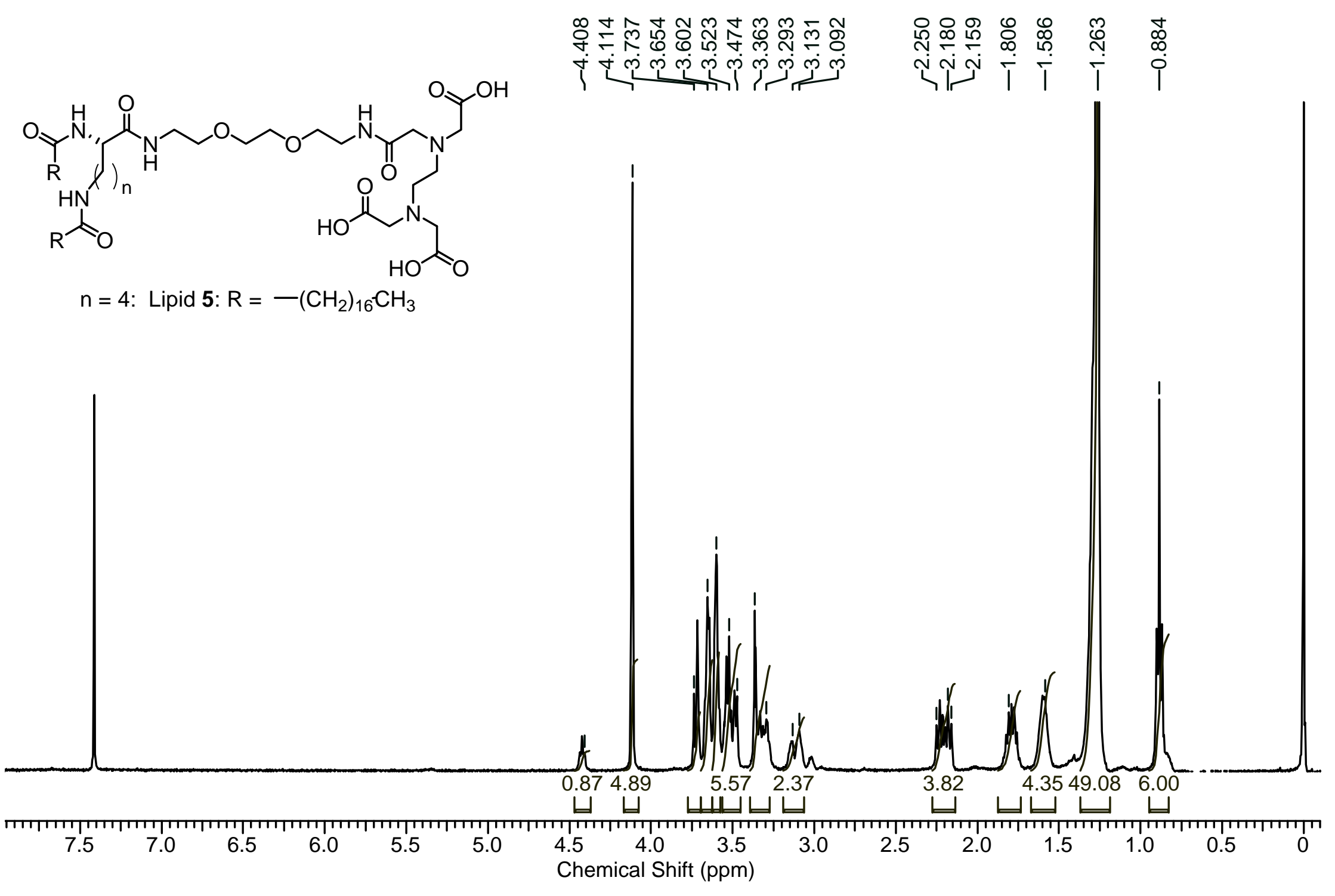




\section{Lipid 5, ${ }^{13} \mathrm{C}$ NMR Spectrum:}

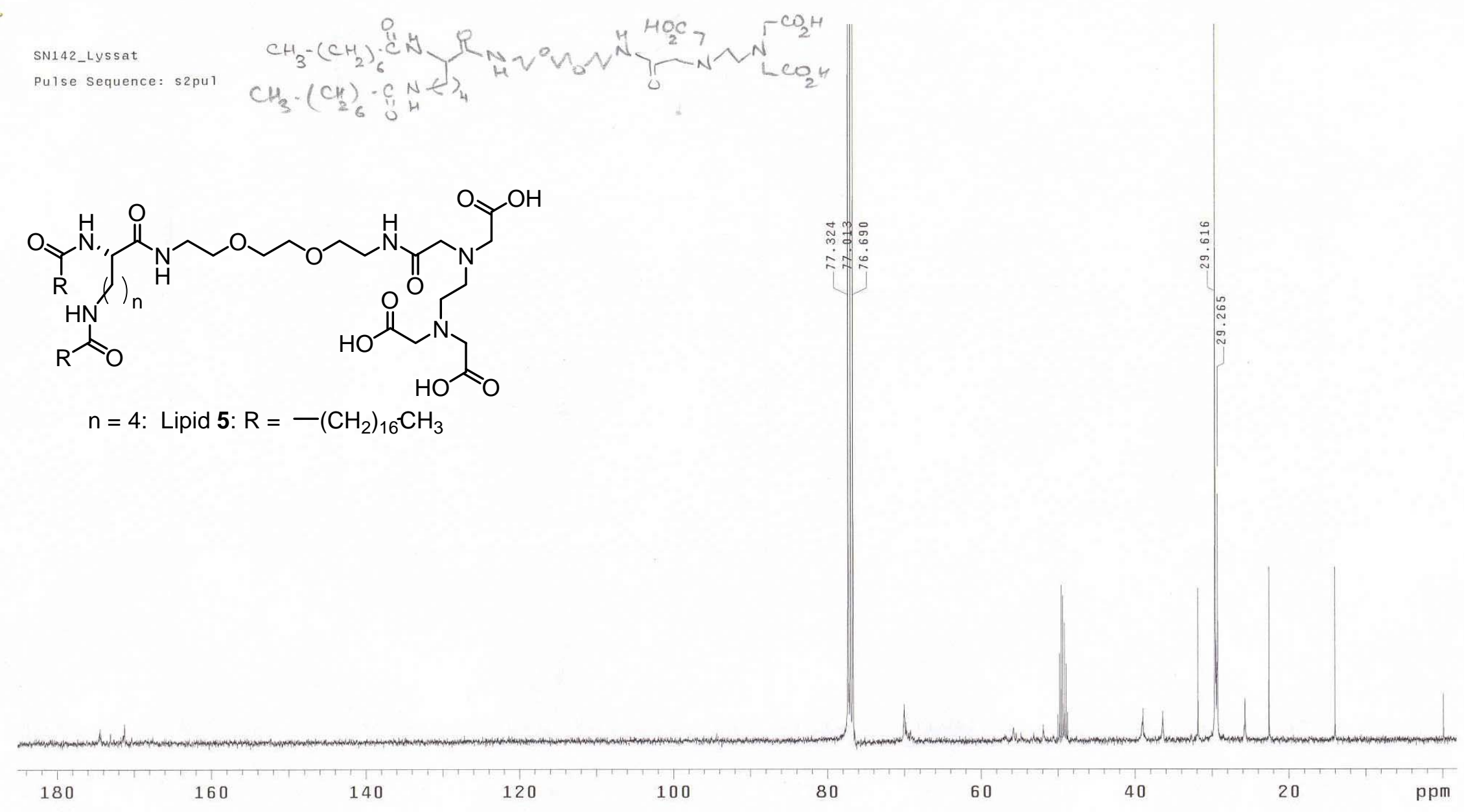




\section{Lipid 6, ${ }^{1 H}$ NMR Spectrum:}

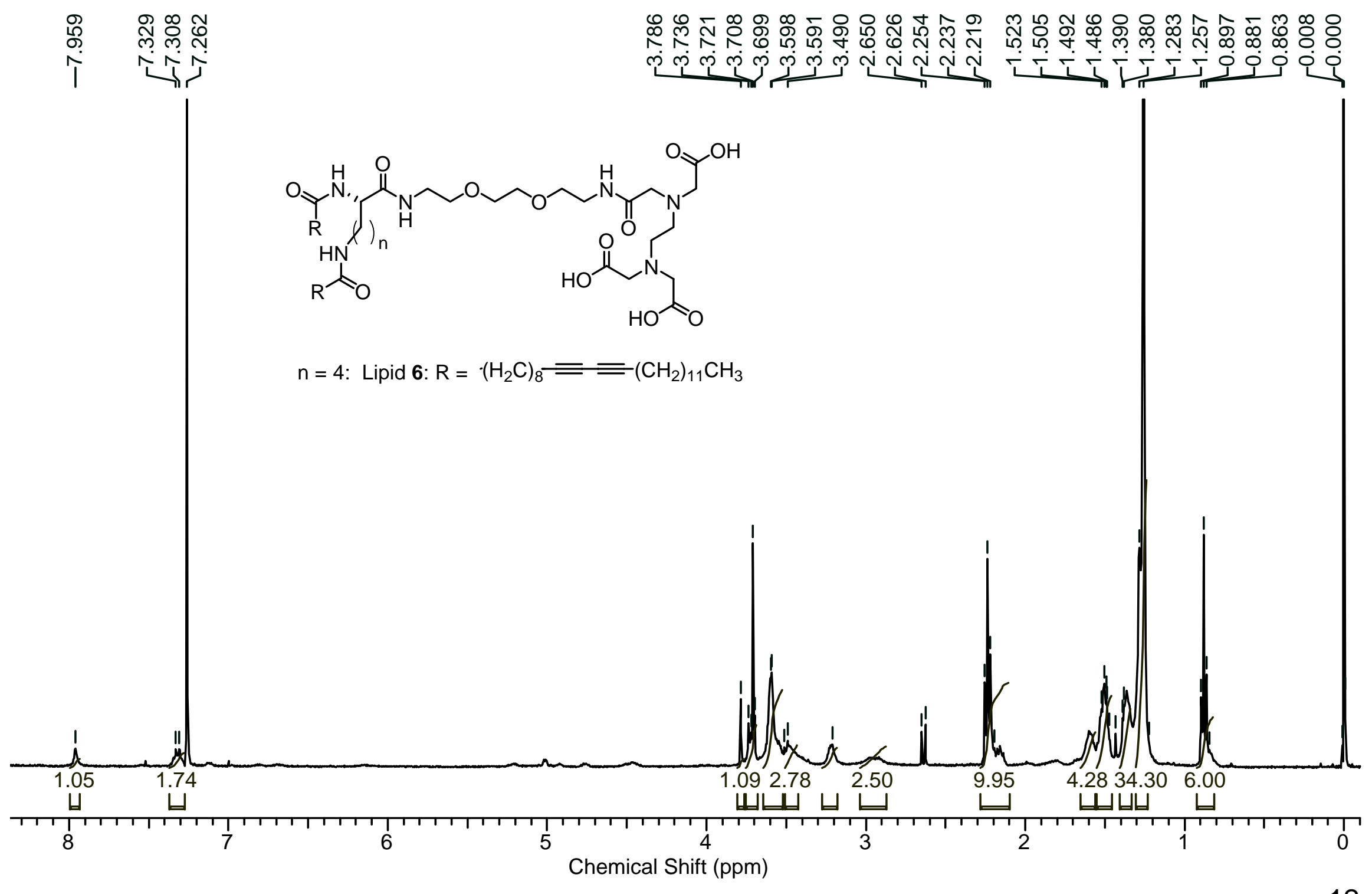




\section{Lipid 6, ${ }^{13}$ C NMR Spectrum:}
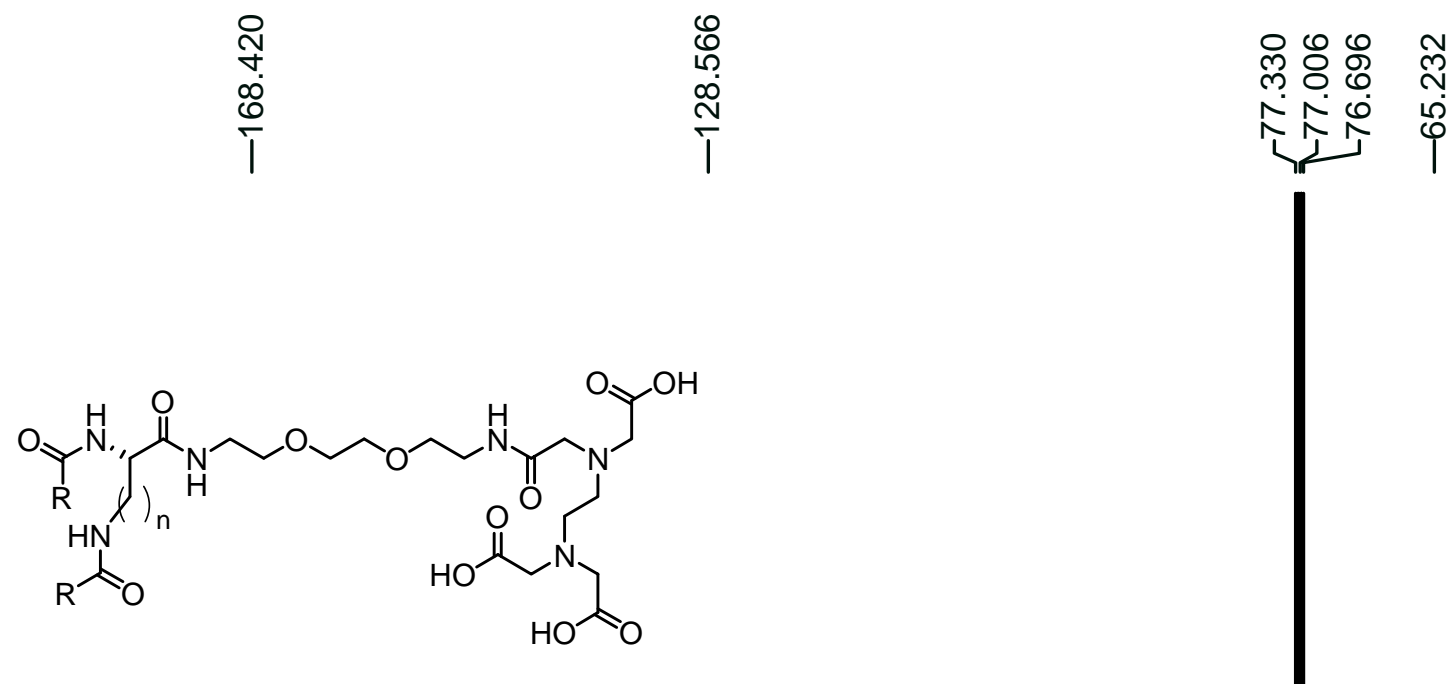

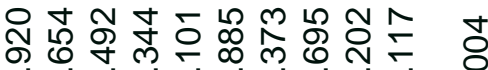

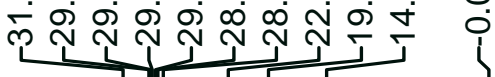

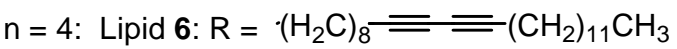

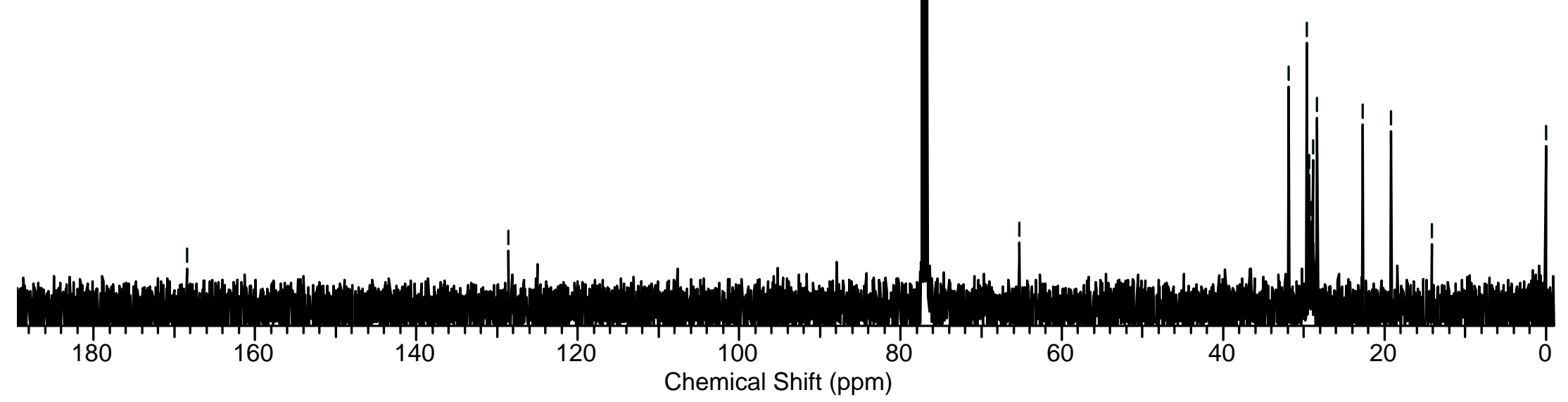




\section{Compound 8, ${ }^{1} \mathrm{H}$ NMR Spectrum:}

TEXP1 MeOH $\mathrm{fr}$

Pulse Sequence: s2pul
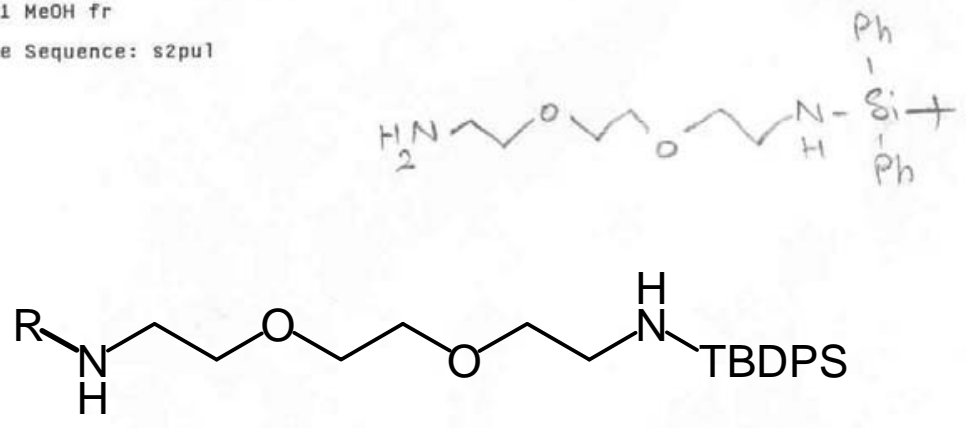

8: $R=H(75 \%)$

9: $\mathrm{R}=\mathrm{TBDPS}(15 \%)$

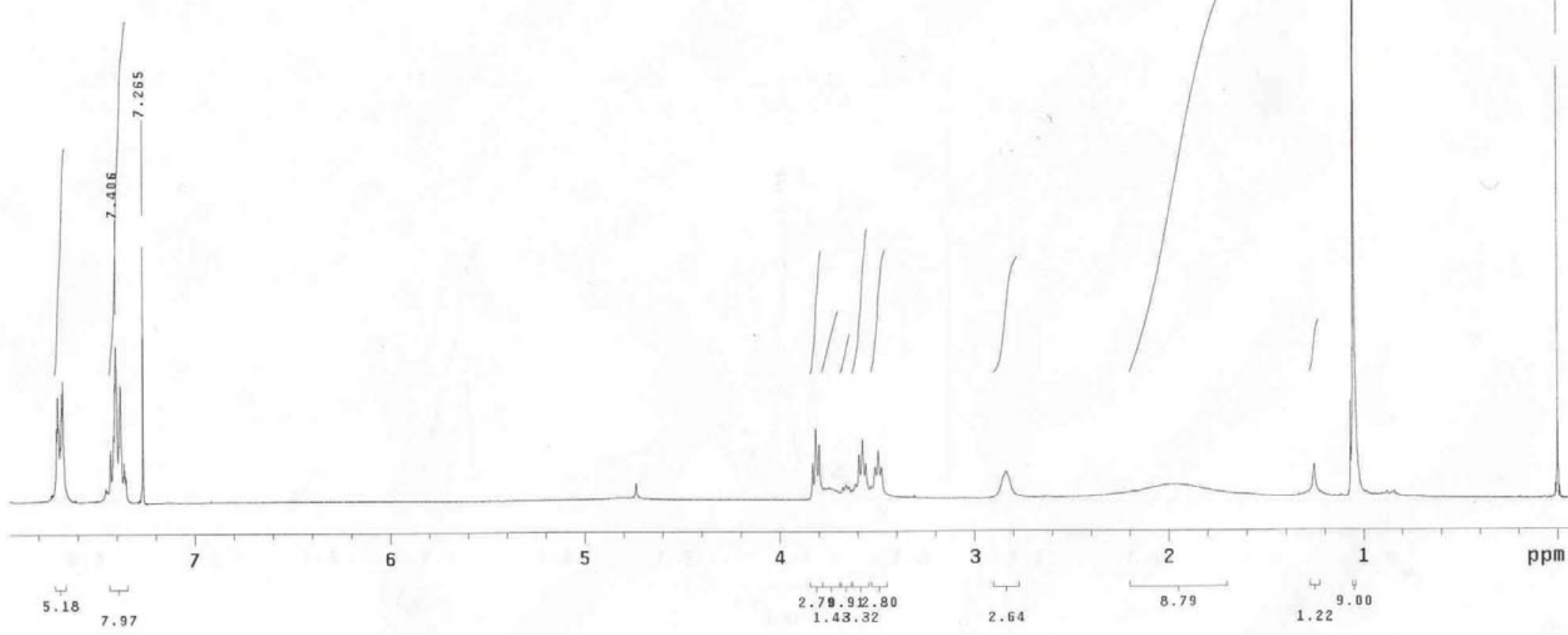




\section{Compound 11, ${ }^{1} \mathrm{H}$ NMR Spectrum:}

PuIse sequence: szpui
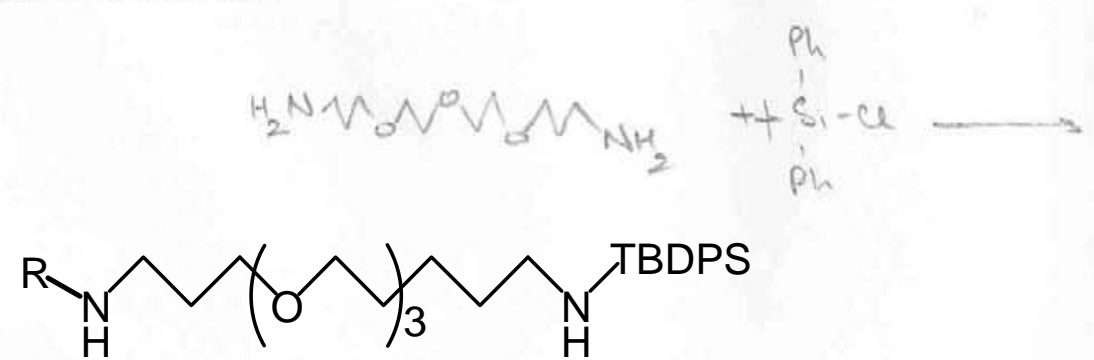

11: $\mathrm{R}=\mathrm{H}(98 \%)$

12: $R=$ TBDPS $(1 \%)$
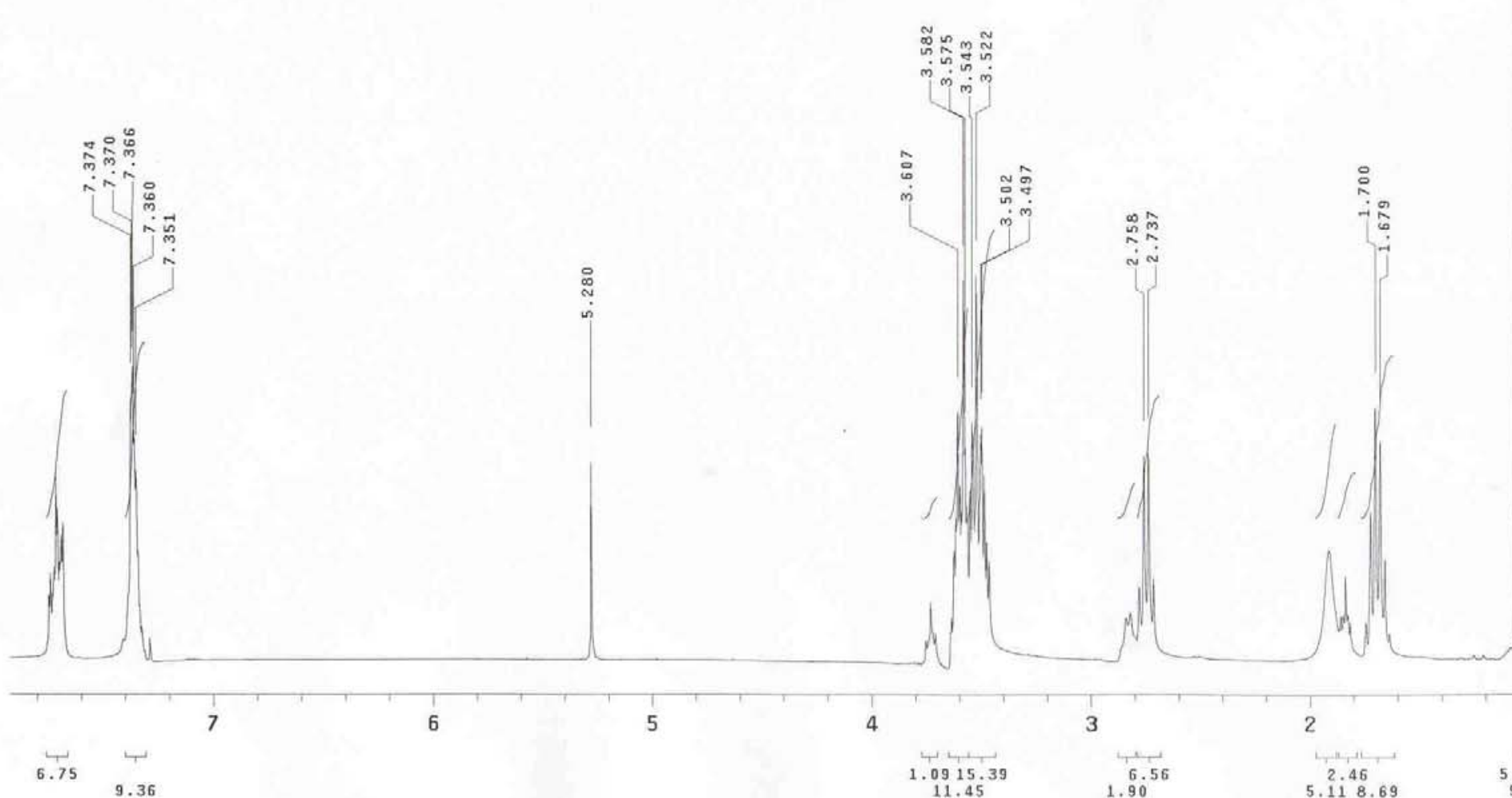

1.0915 .39
11.45

$1.90^{6.56}$

2.46
5.118 .69 


\section{Compound 19a, ${ }^{1 H}$ NMR Spectrum:}

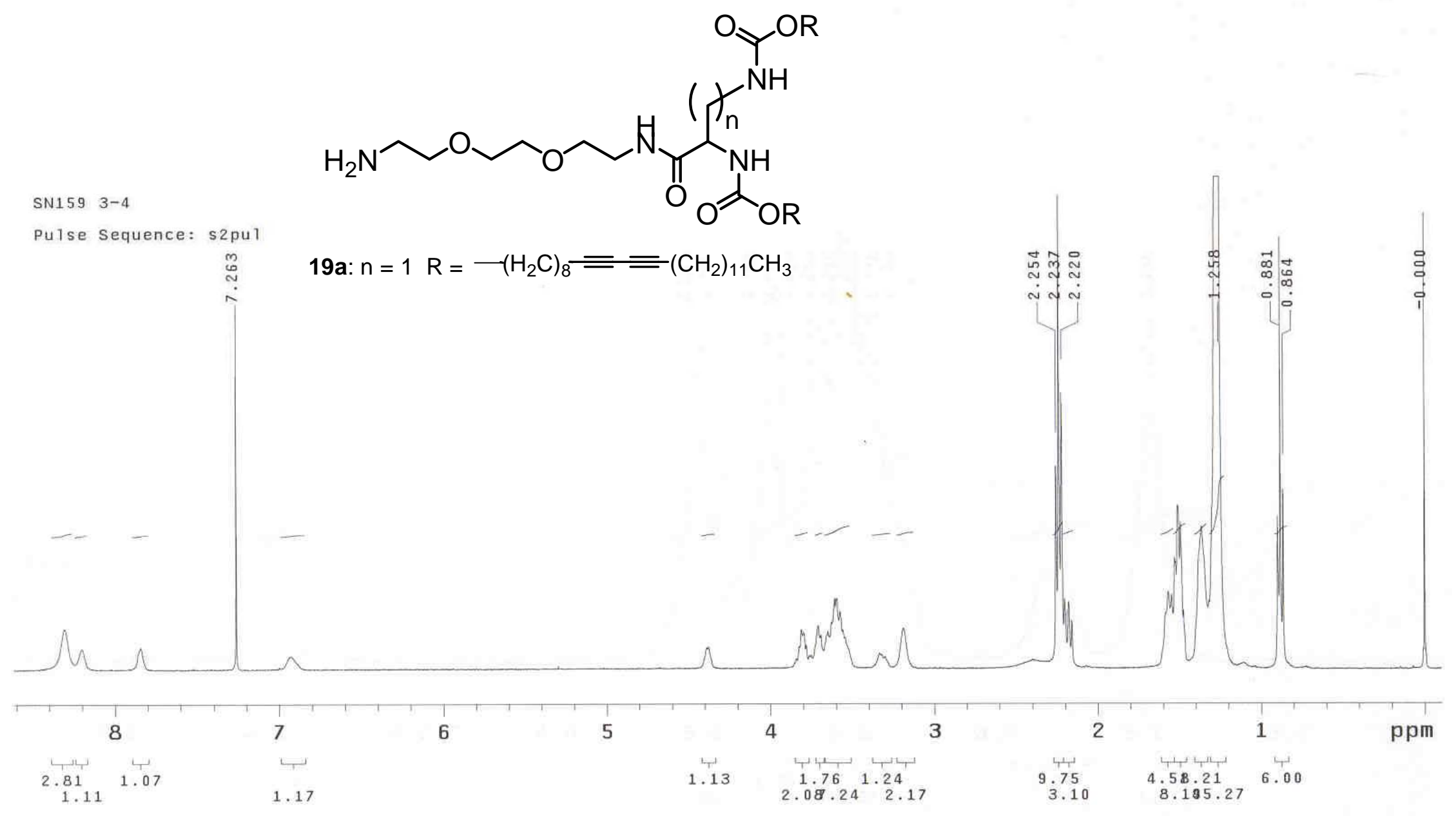




\section{Compound 19b, ${ }^{1} \mathrm{H}$ NMR Spectrum:}

Pulse Sequence: s2pul
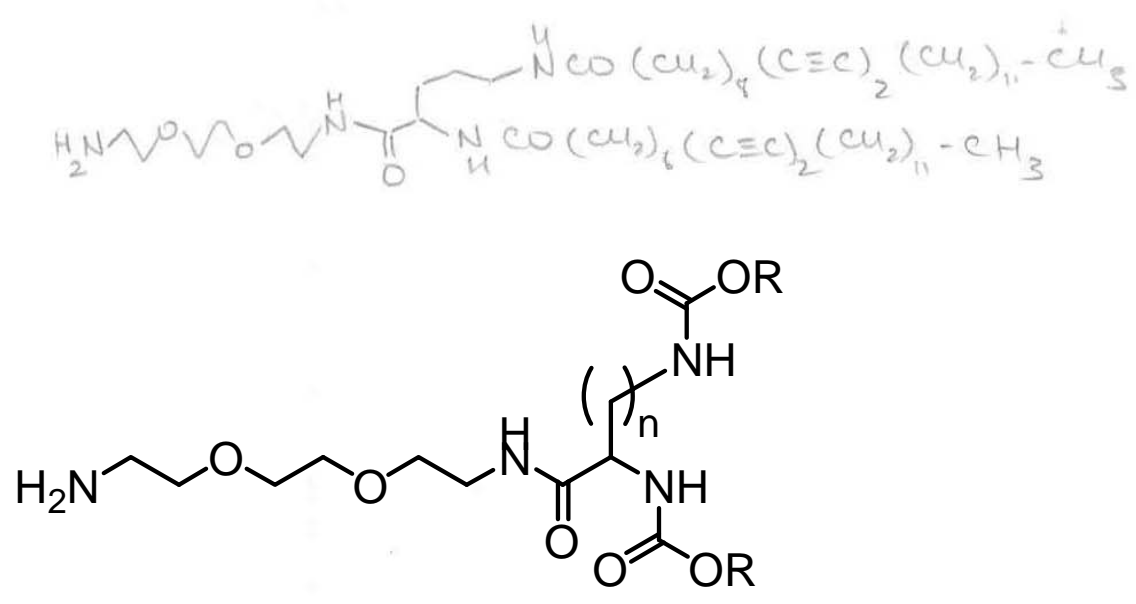

19b: $n=3 \quad \mathrm{R}=-\left(\mathrm{H}_{2} \mathrm{C}\right)_{8}=\equiv\left(\mathrm{CH}_{2}\right)_{11} \mathrm{CH}_{3}$

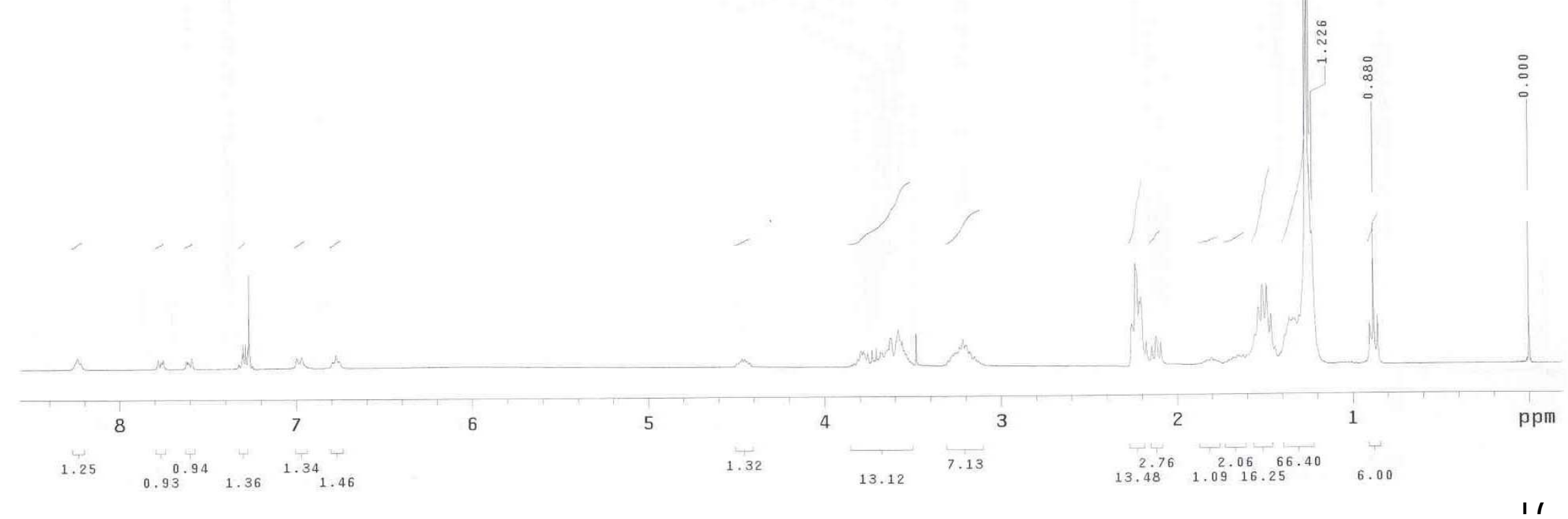




\section{Compound 19c, ${ }^{1} \mathrm{H}$ NMR Spectrum:}

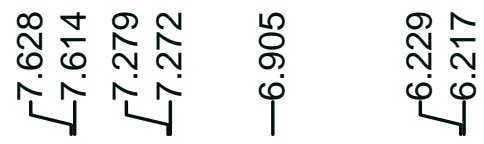<smiles>[R]OC(=O)NC(C)C(=O)NCCOCCOCCN</smiles>

19c: $\mathrm{n}=4 \mathrm{R}=-\left(\mathrm{H}_{2} \mathrm{C}\right)_{8}=\equiv\left(\mathrm{CH}_{2}\right)_{11} \mathrm{CH}_{3}$

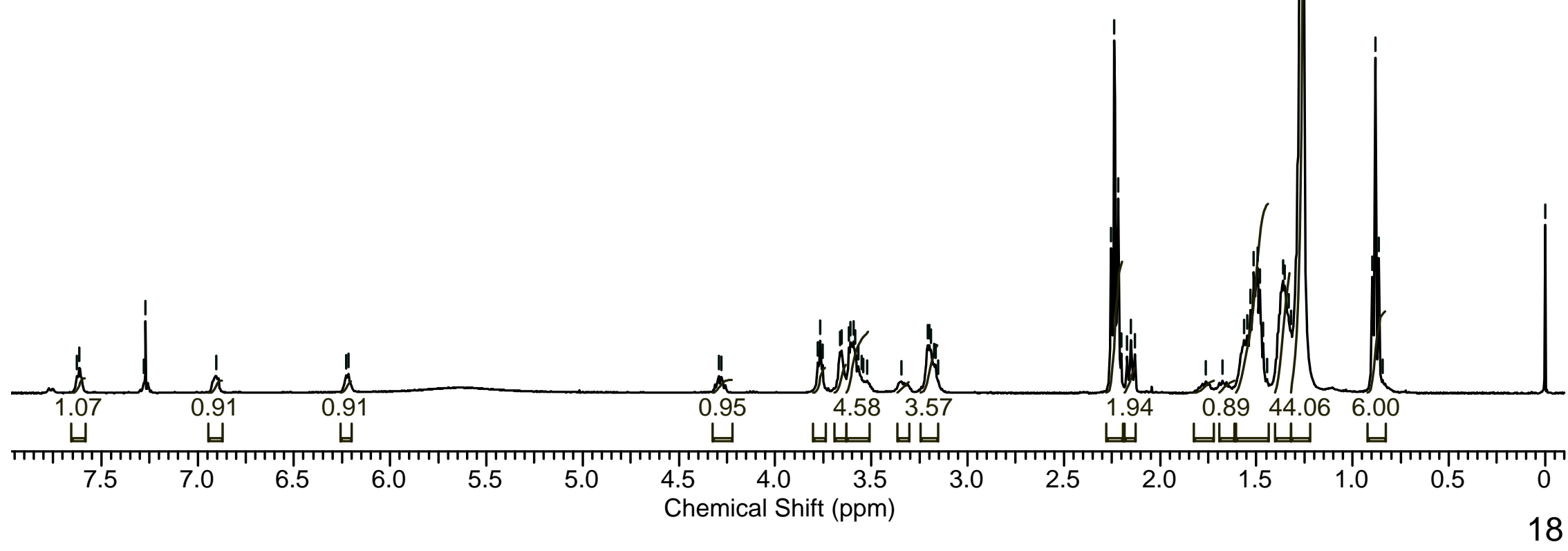




\section{Compound 19c, ${ }^{13} \mathrm{C}$ NMR Spectrum:}
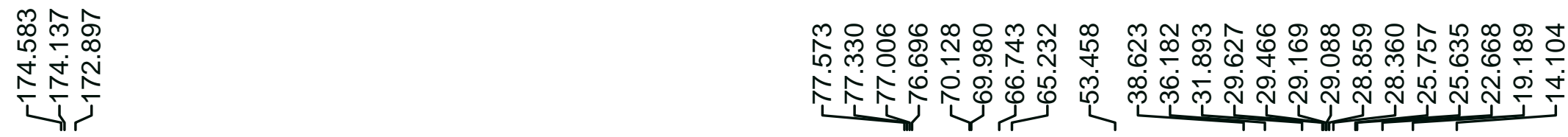

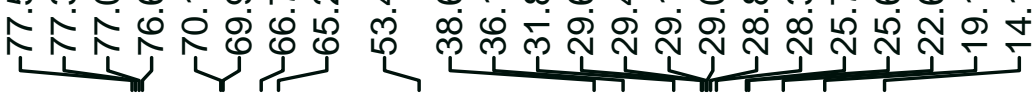<smiles>[R]OC(=O)NC(C)C(=O)NCCOCCOCCN</smiles>

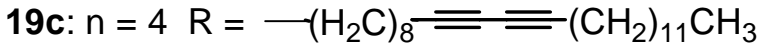

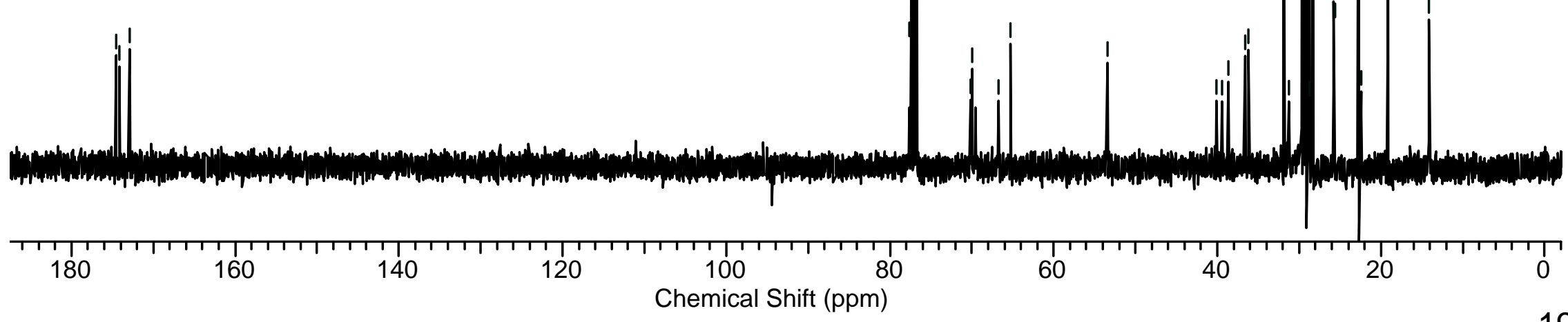




\section{Compound 19d, ${ }^{1} \mathrm{H}$ NMR Spectrum:}

Pulse Sequence: sapur

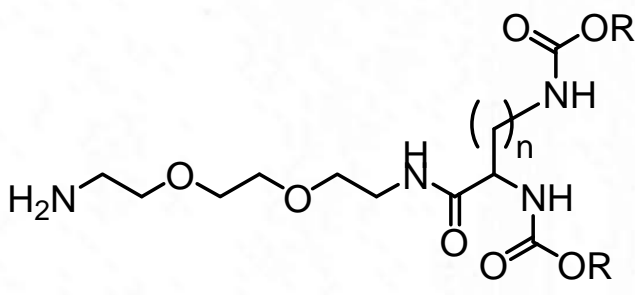

$19 d: n=3 \quad R=-\left(\mathrm{CH}_{2}\right)_{16} \mathrm{CH}_{3}$

8

0.20 $0.24^{0.22}$ 


\section{Compound 19d, ${ }^{13} \mathrm{C}$ NMR Spectrum:}

exp\#77 Orn_stearate 130

Pulse Sequence: s2pul

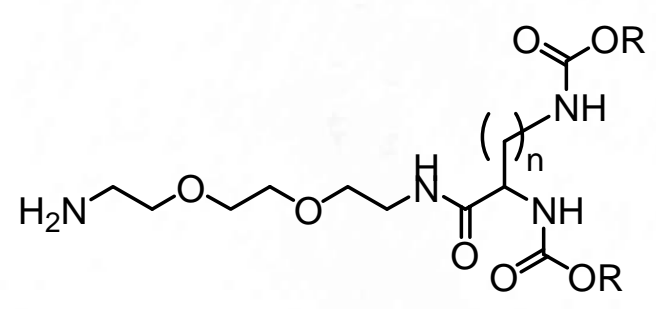

$19 \mathrm{~d}: \mathrm{n}=3 \mathrm{R}=-\left(\mathrm{CH}_{2}\right)_{16} 6 \mathrm{CH}_{3}$

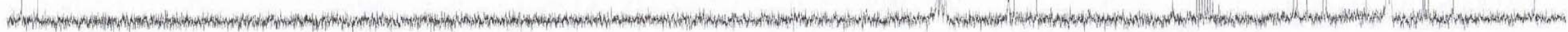




\section{Compound $19 \mathrm{e},{ }^{1} \mathrm{H}$ NMR Spectrum:}
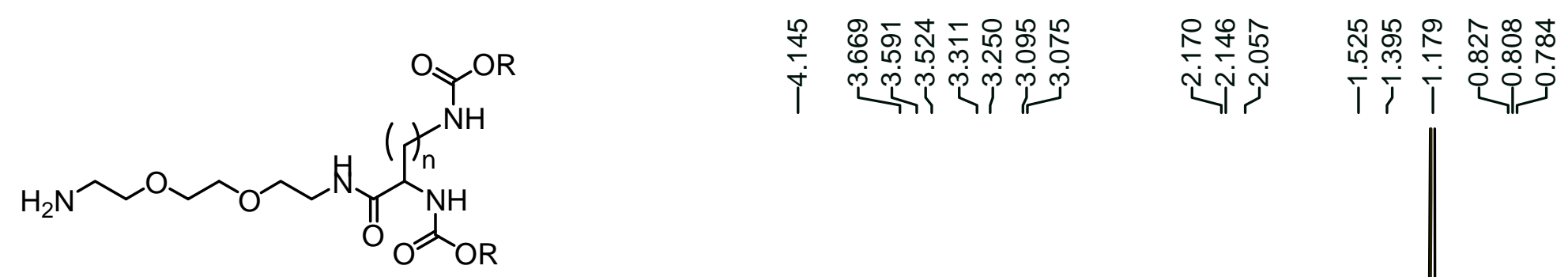

$19 e: n=4 \quad R=-\left(\mathrm{CH}_{2}\right)_{16} C \mathrm{CH}_{3}$

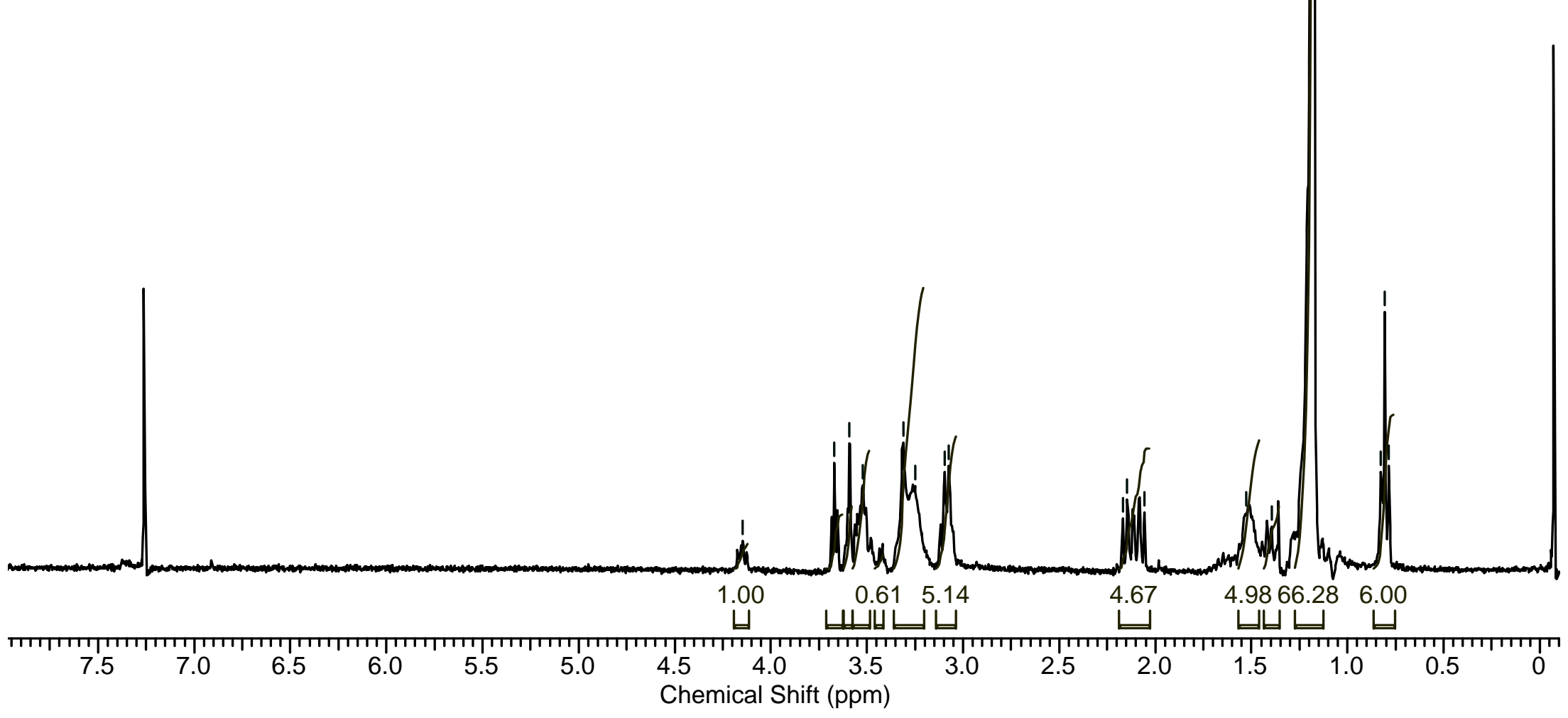




\section{Compound 20a, ${ }^{1} \mathrm{H}$ NMR Spectrum:}

SN188_1

Pulse Sequence: s2pul
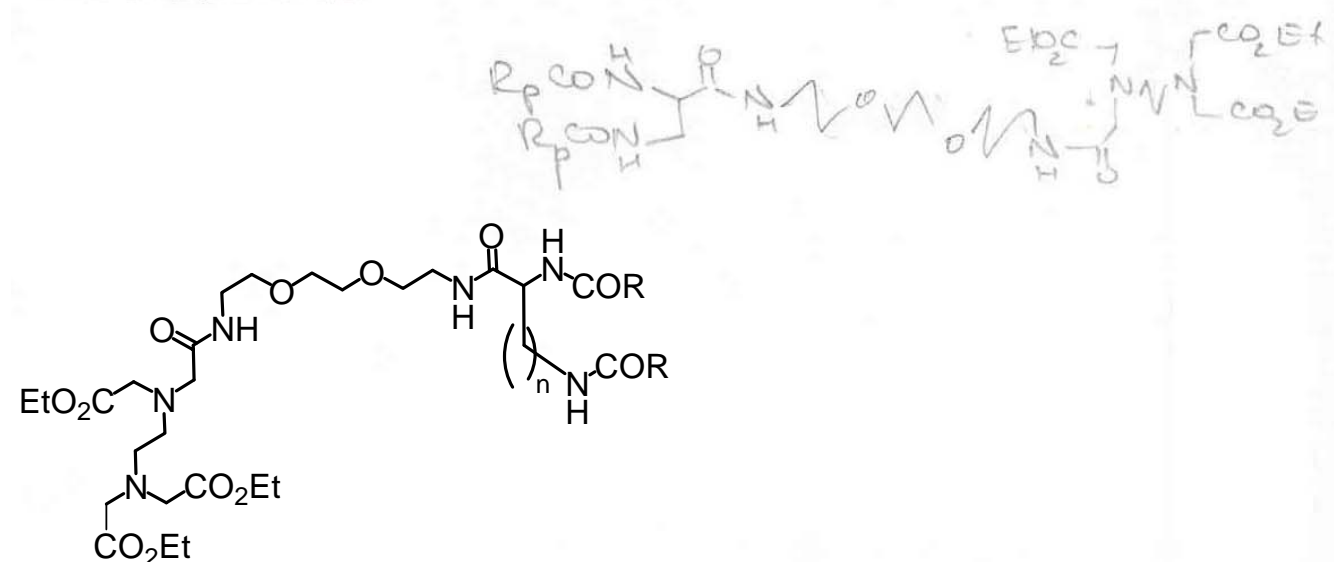

20a: $n=1 \quad \mathrm{R}=-\left(\mathrm{H}_{2} \mathrm{C}\right)_{8} \equiv \equiv\left(\mathrm{CH}_{2}\right)_{11} \mathrm{CH}_{3}$

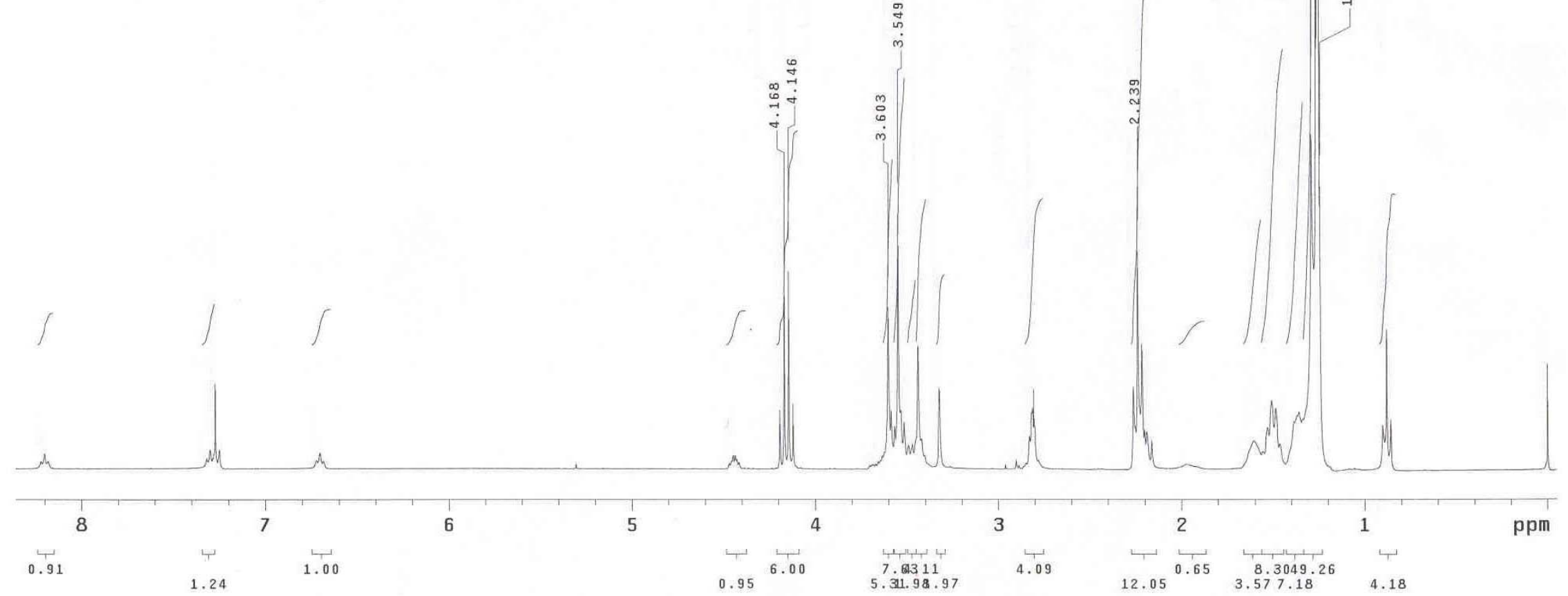




\section{Compound 20a, ${ }^{13} \mathrm{C}$ NMR Spectrum:}

SN188_1

Pulse Sequence: s2pul
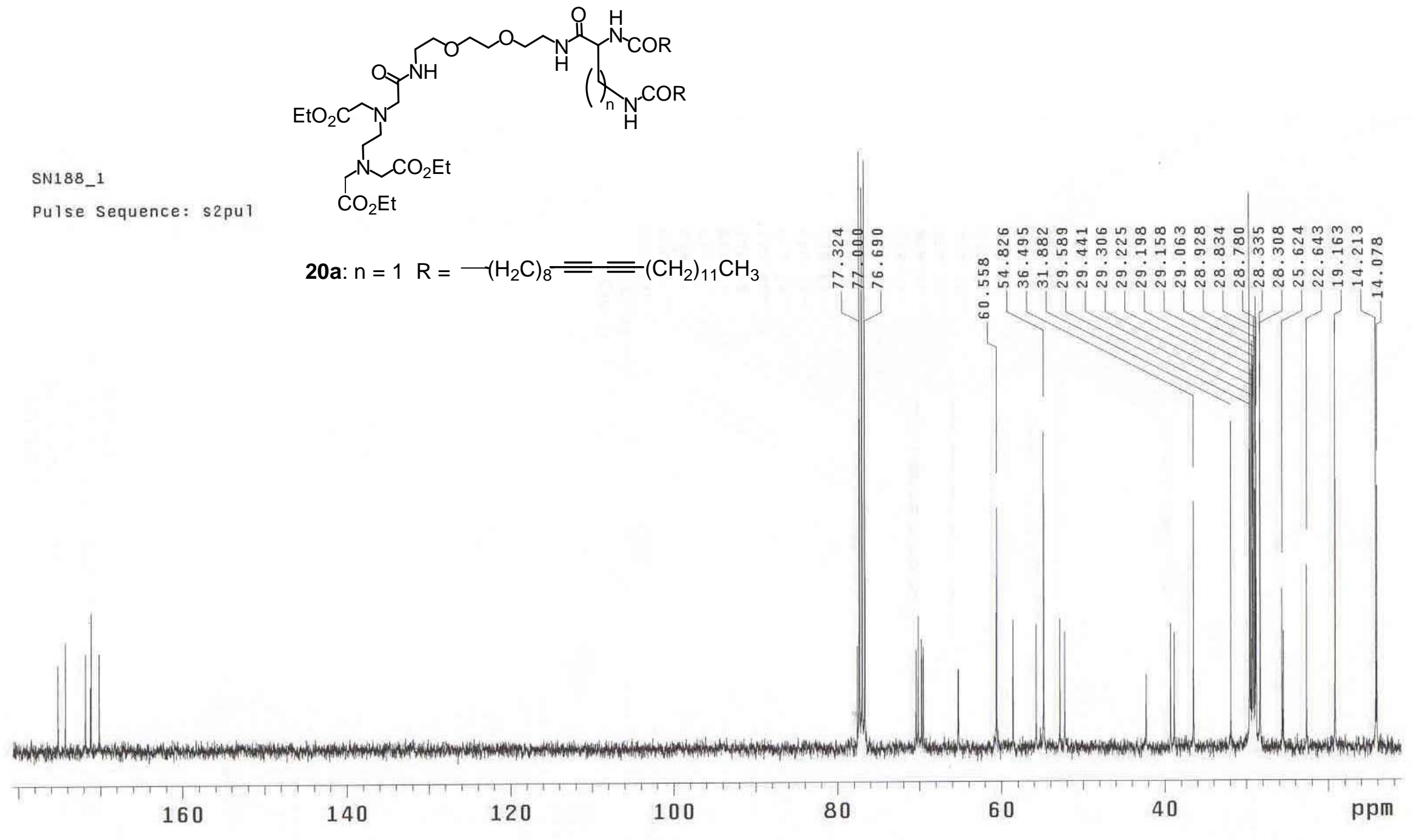


\section{Compound 20b, ${ }^{1} \mathrm{H}$ NMR Spectrum:}

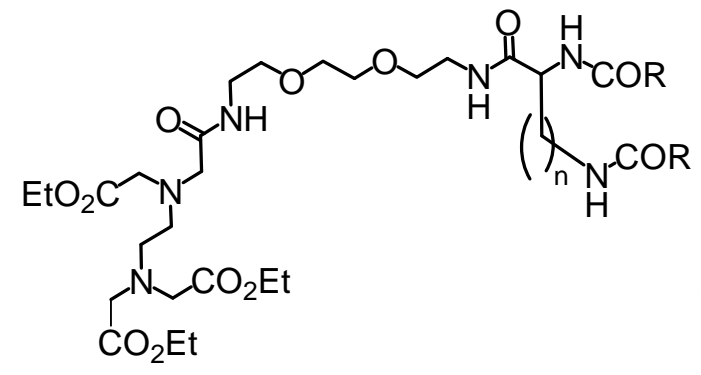

20b: $n=3 \quad \mathrm{R}=-\left(\mathrm{H}_{2} \mathrm{C}\right)_{8}=\left(\mathrm{CH}_{2}\right)_{11} \mathrm{CH}_{3}$

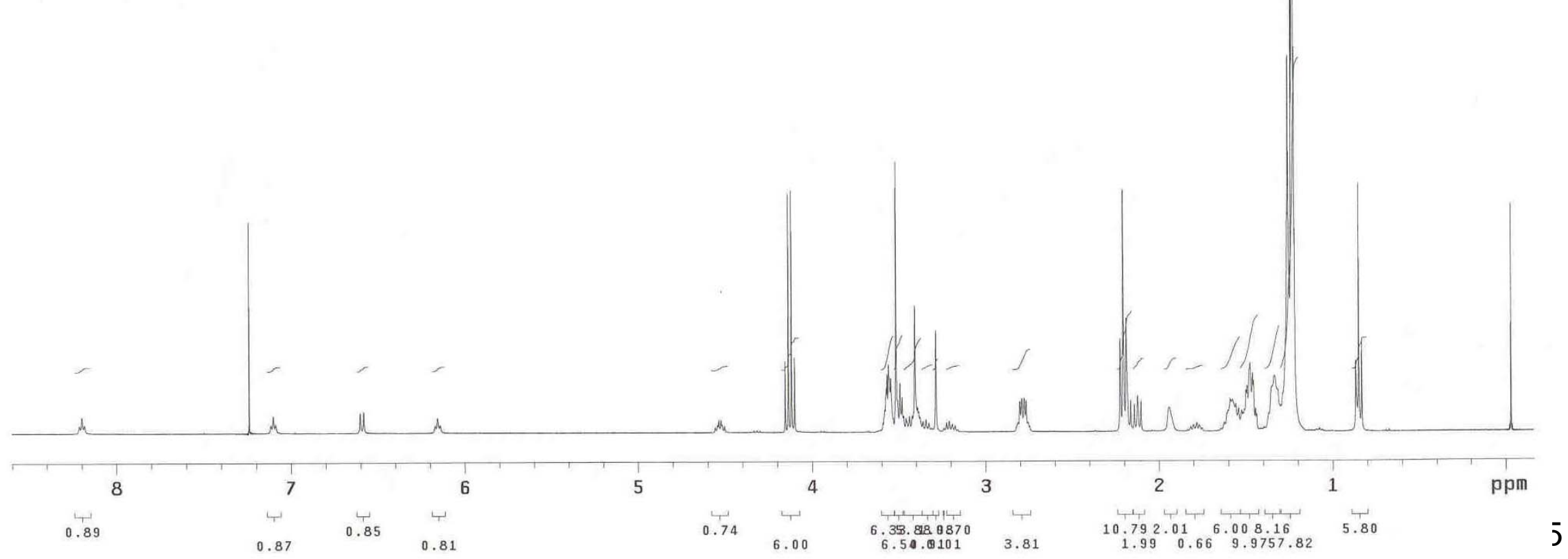




\section{Compound 20b, ${ }^{13} \mathrm{C}$ NMR Spectrum:}

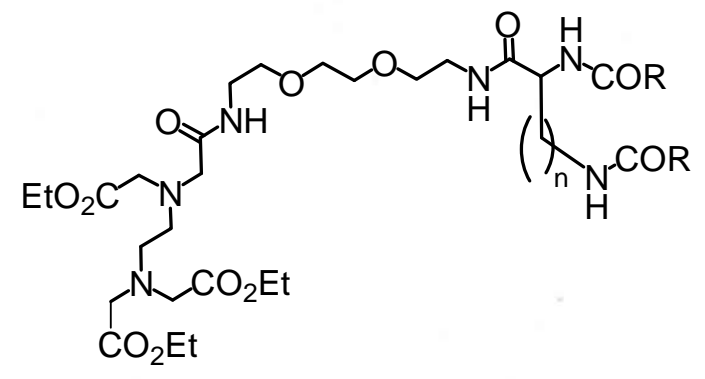

20b: $n=3 \quad \mathrm{R}=-\left(\mathrm{H}_{2} \mathrm{C}\right)_{8}=\equiv\left(\mathrm{CH}_{2}\right)_{11} \mathrm{CH}_{3}$
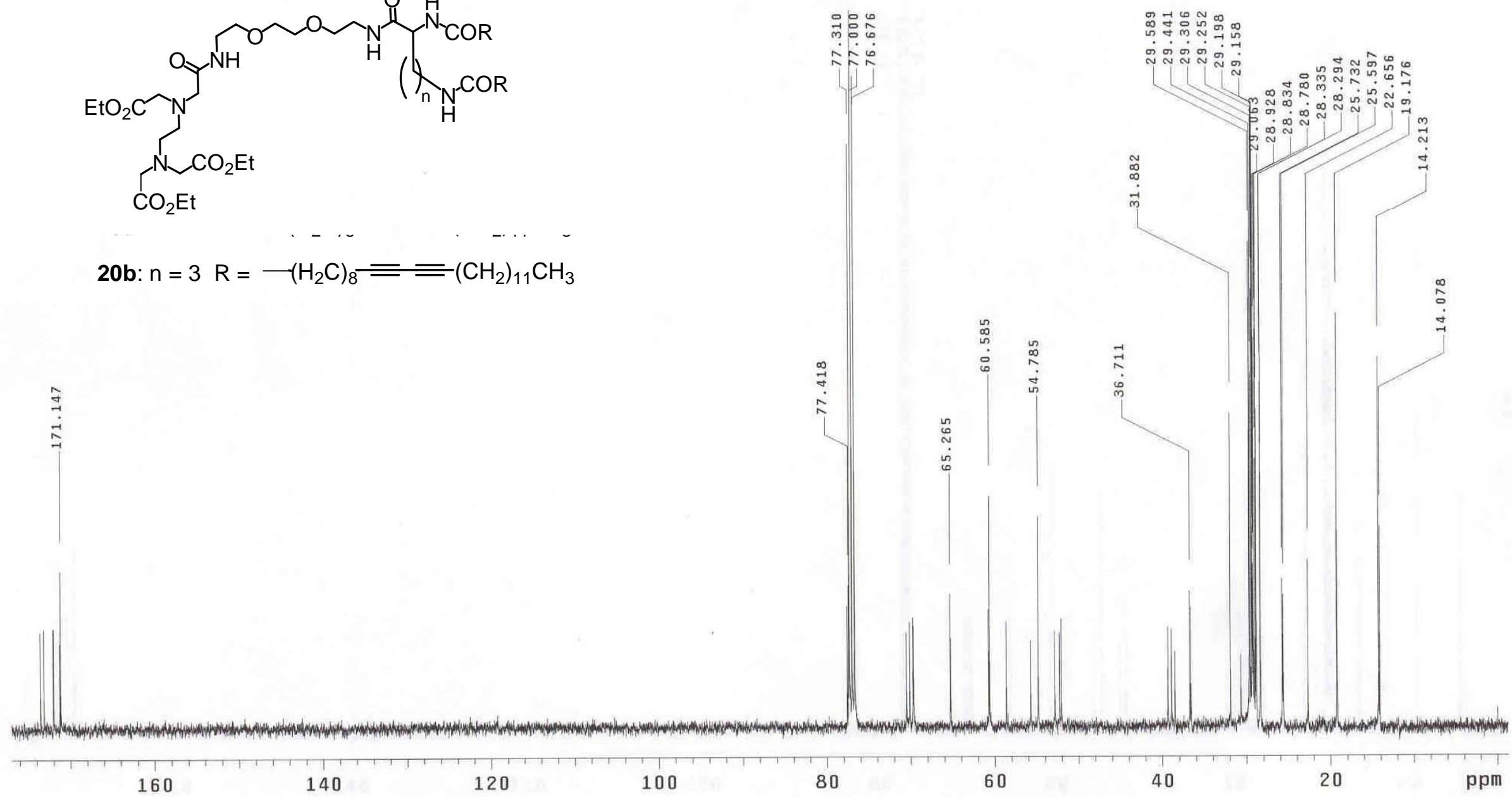


\section{Compound 20c, ${ }^{1} \mathrm{H}$ NMR Spectrum:}

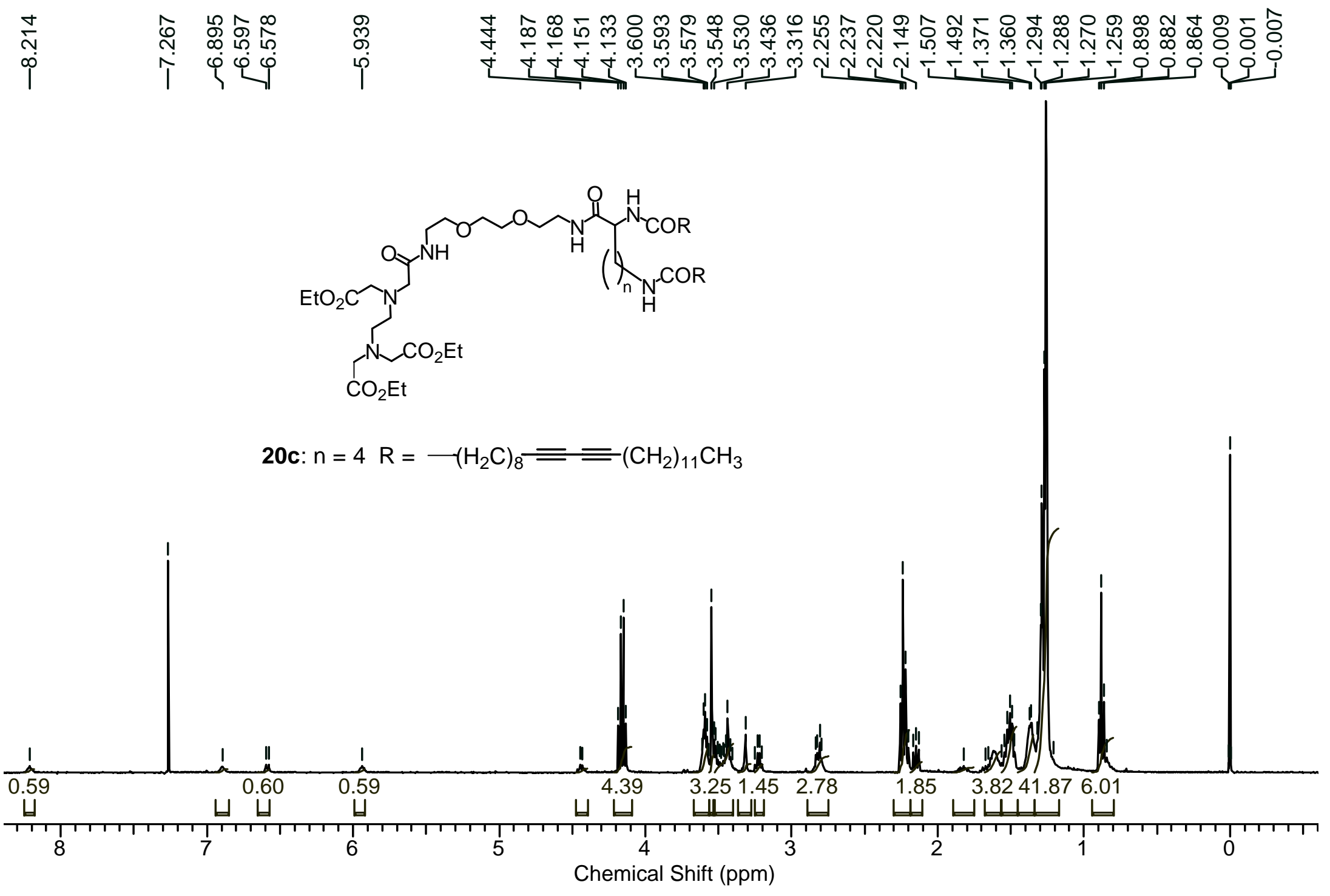




\section{Compound 20c, ${ }^{13} \mathrm{C}$ NMR Spectrum:}

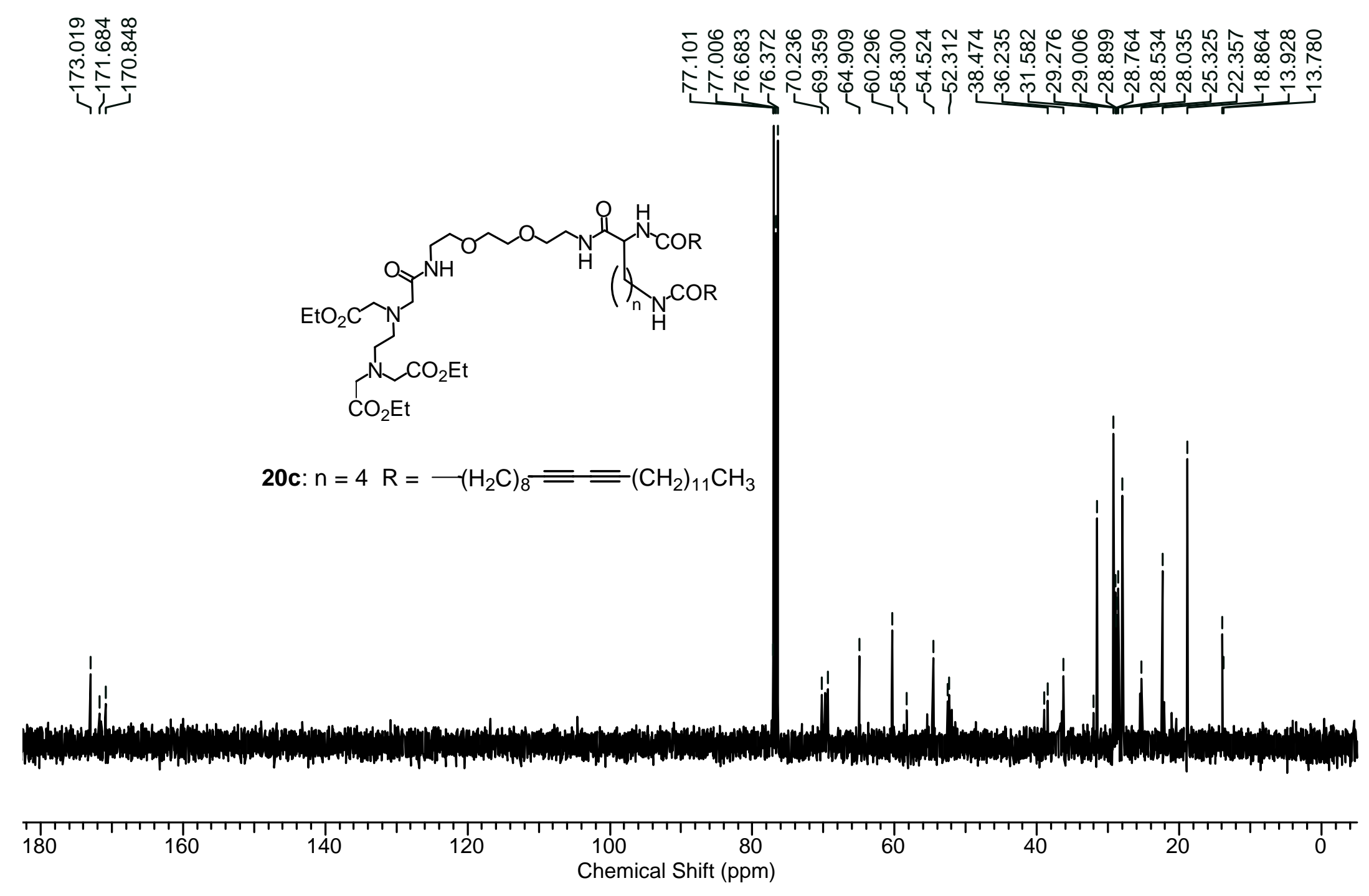




\section{Compound 20d, ${ }^{1} \mathrm{H}$ NMR Spectrum:}

SN138_2

Pulse Sequence: $s 2 \mathrm{pu}$

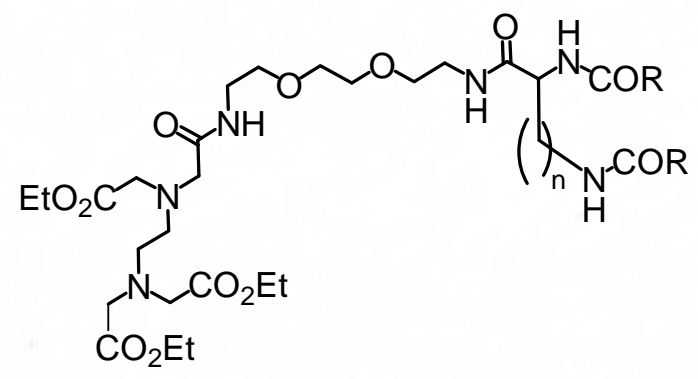

20d: $n=3 \quad R=-\left(\mathrm{CH}_{2}\right)_{16} \mathrm{CH}_{3}$

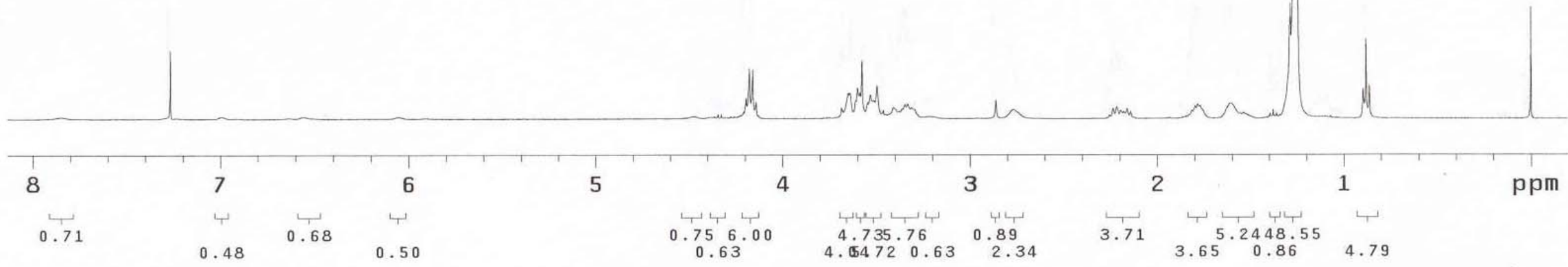




\section{Compound 20e, ${ }^{1} \mathrm{H}$ NMR Spectrum:}

\section{leFactor $=1$}

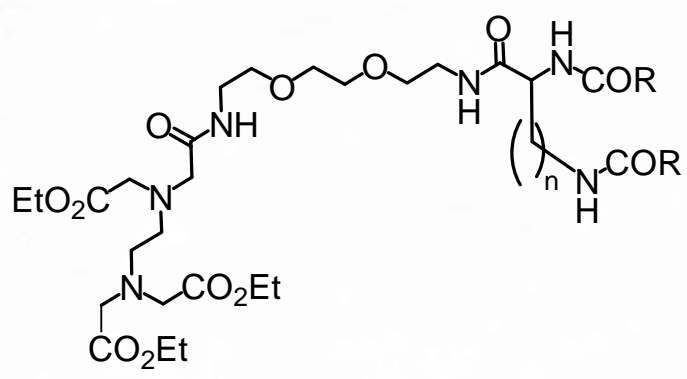

20e: $n=4 \quad \mathrm{R}=-\left(\mathrm{CH}_{2}\right)_{16} \mathrm{CH}_{3}$

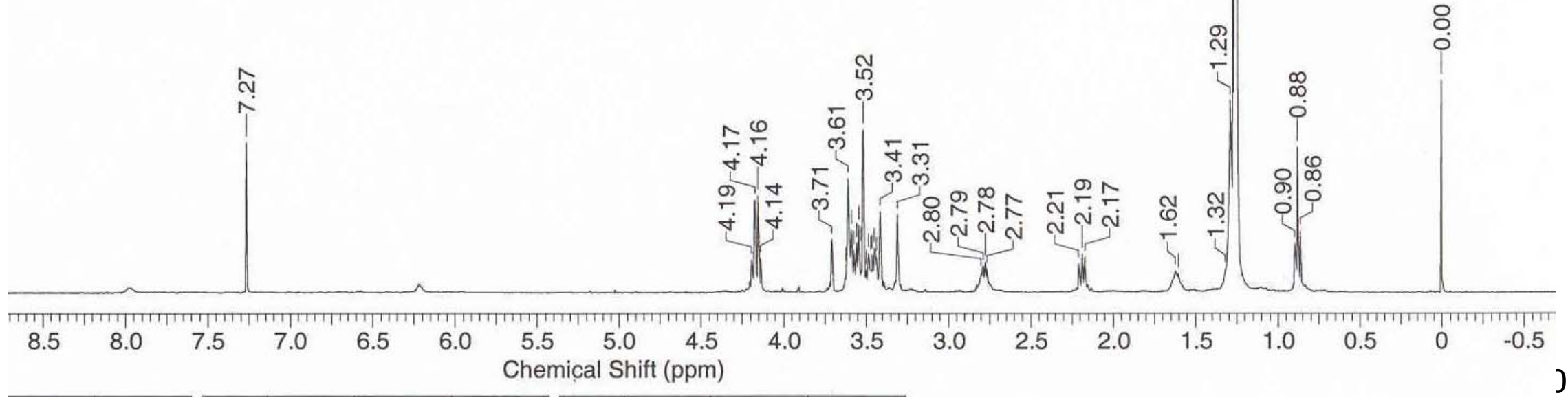




\section{Compound $20 \mathrm{e},{ }^{13} \mathrm{C}$ NMR Spectrum:}
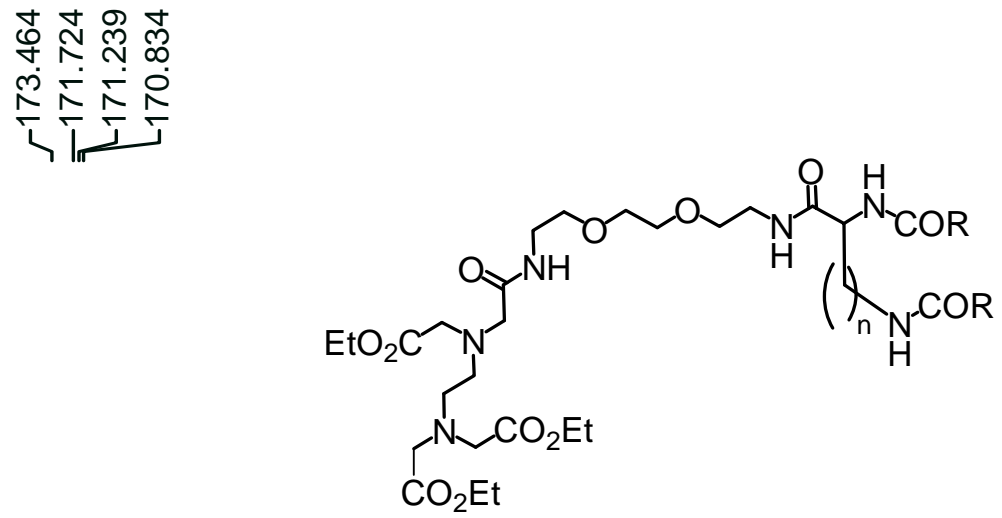

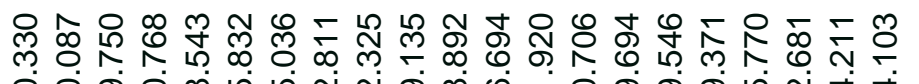
운

20e: $n=4 \quad R=-\left(\mathrm{CH}_{2}\right)_{16} \mathrm{CH}_{3}$

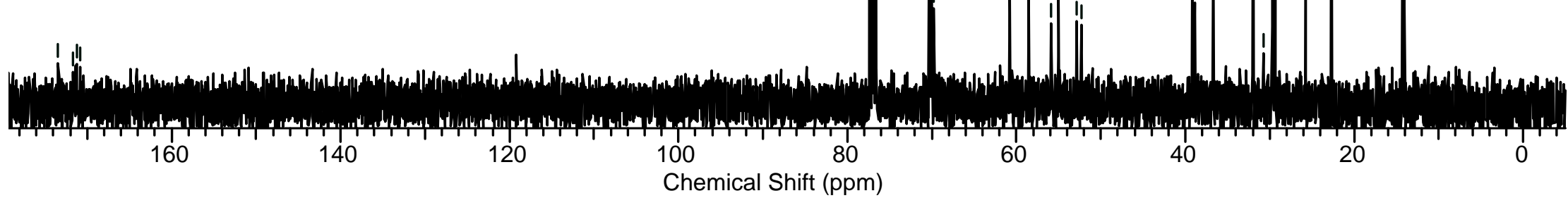




\section{Compound 24, ${ }^{1} \mathrm{H}$ NMR Spectrum:}

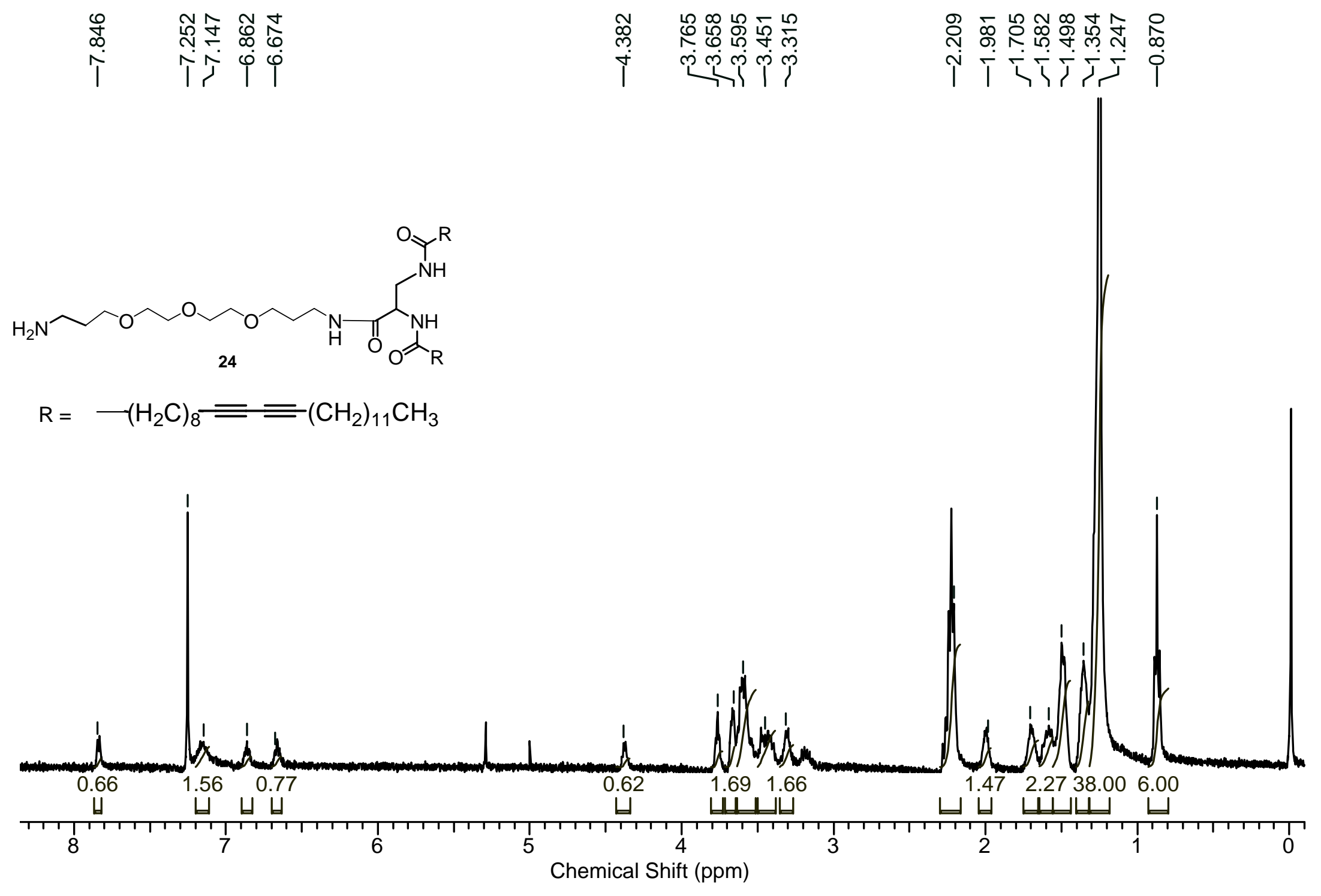




\section{Compound $24,{ }^{13} \mathrm{C}$ NMR Spectrum:}

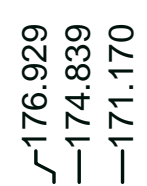

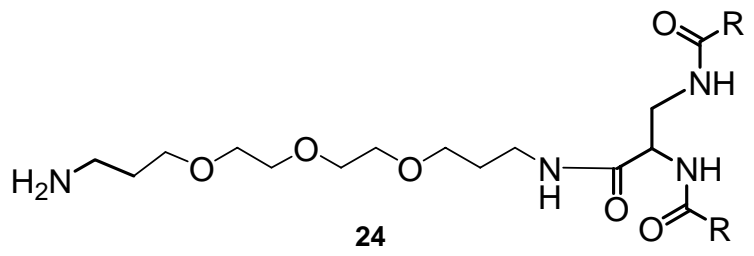

$\mathrm{R}=\longrightarrow\left(\mathrm{H}_{2} \mathrm{C}\right)_{8}=\left(\mathrm{CH}_{2}\right)_{11} \mathrm{CH}_{3}$
மำ

손

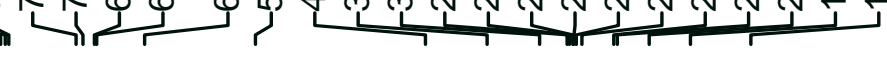

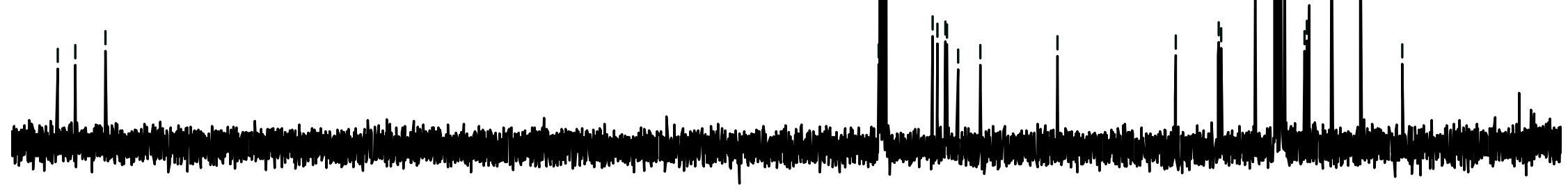

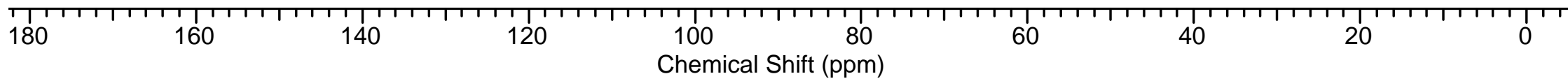




\section{Compound $25,{ }^{1} \mathrm{H}$ NMR Spectrum:}

\section{SN187_3}

Pulse Sequence: s2pul

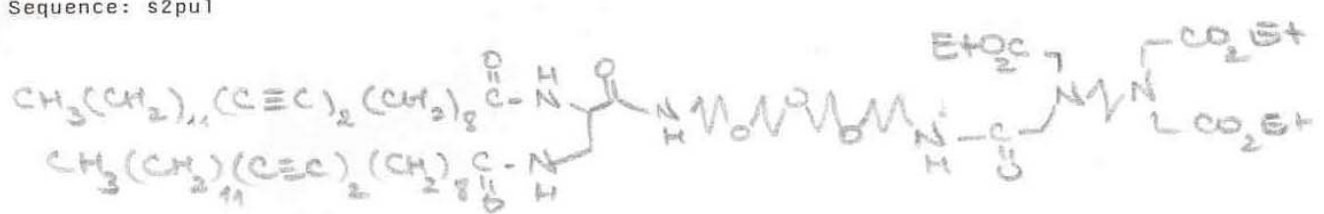<smiles>[R]C(=O)NC[C@H](NC([R])=O)C(=O)NCCCOCCOCCOCCCNC(=O)CN(CCOCC)CCN(CCOCC)CC(=O)OCC</smiles>

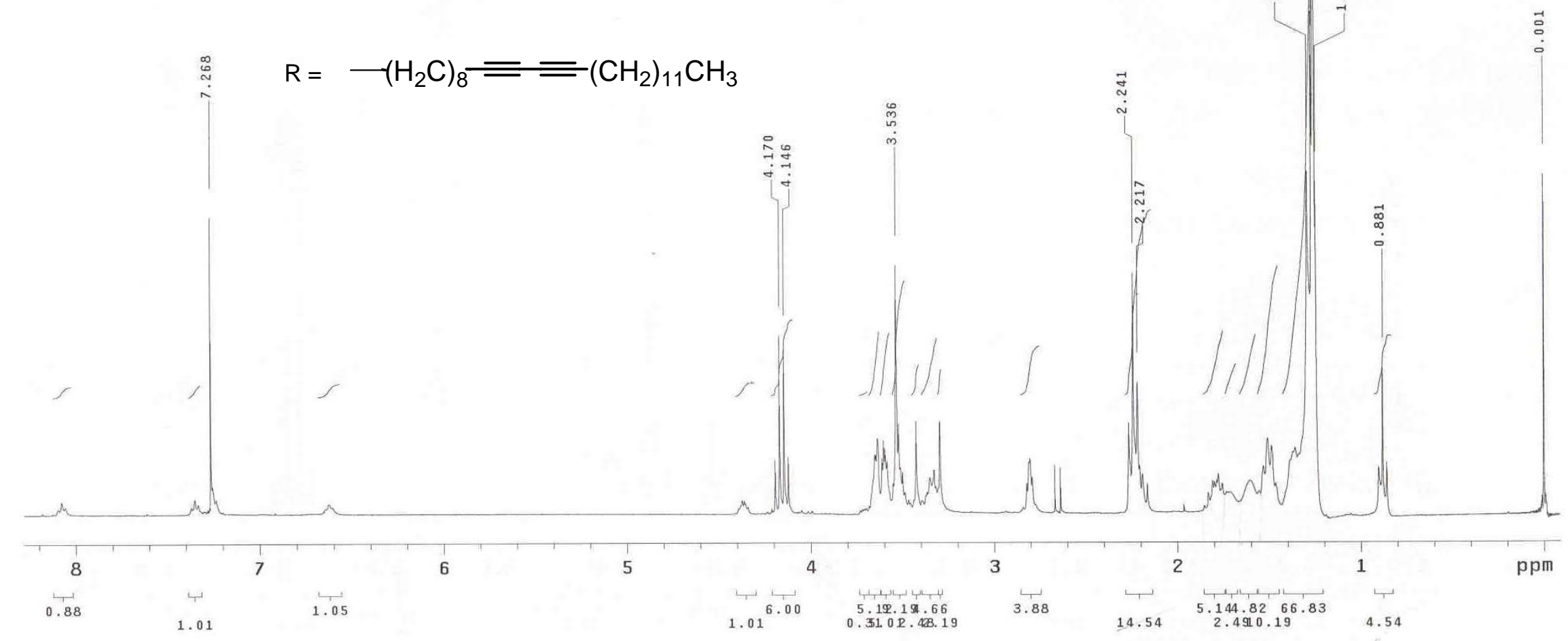




\section{Compound 25, ${ }^{13} \mathrm{C}$ NMR Spectrum:}

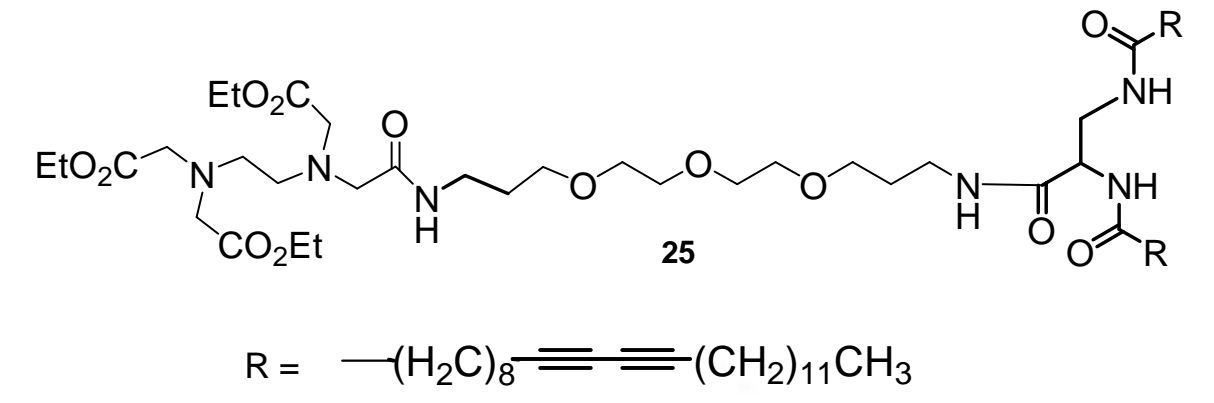

SN187_3

Pulse Sequence: s2pul

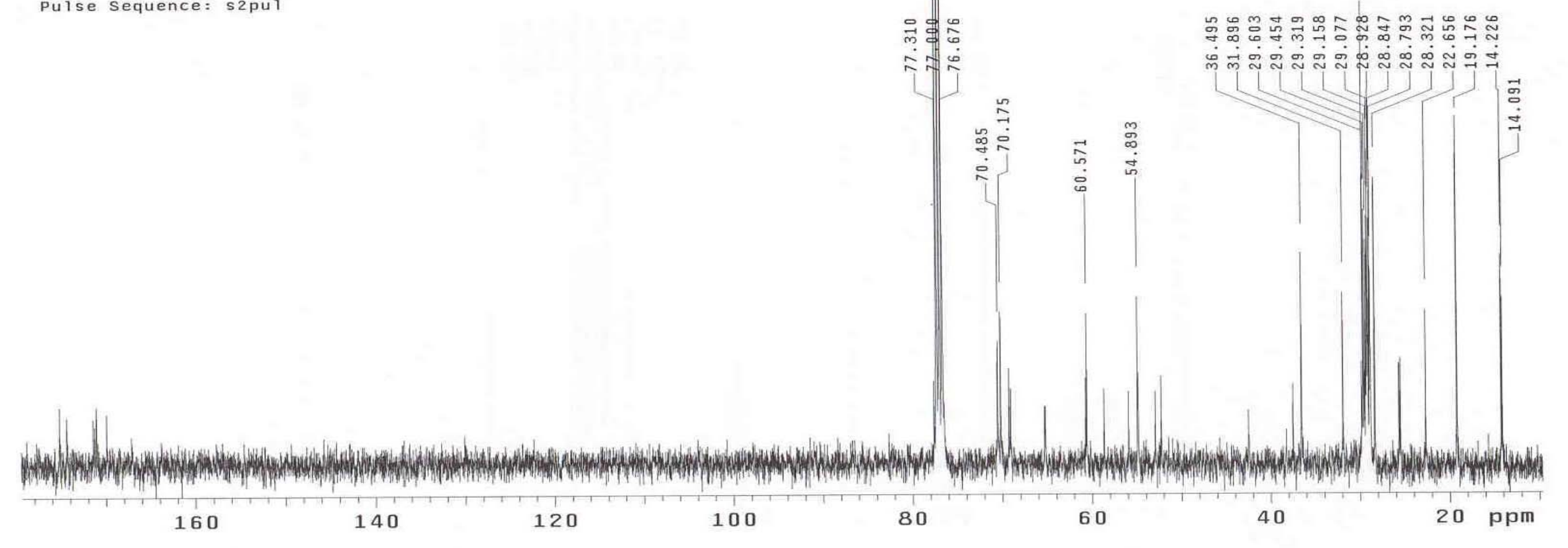

